\title{
PATTERNS OF BILATERAL ASYMMETRY AND ALLOMETRY IN LATE DEVONIAN POLYGNATHUS CONODONTS
}

\author{
by SABRINA RENAUD ${ }^{1}$ (D), BEVERLEY ECALLE ${ }^{2}$ (D), PÉNÉLOPE CLAISSE ${ }^{2}$ (D), \\ ANNE-LISE CHARRUAULT ${ }^{2}$, RONAN LEDEVIN ${ }^{1,3}$ (D) and \\ CATHERINE GIRARD ${ }^{2}$ \\ ${ }^{1}$ Laboratoire de Biométrie et Biologie Evolutive, UMR 5558 CNRS, Université Claude Bernard Lyon 1, Université de Lyon, 69100 Villeurbanne, France \\ ${ }^{2}$ Institut des Sciences de l'Evolution de Montpellier (ISEM), Université Montpellier, CNRS, EPHE, IRD, Montpellier, France; catherine.girard@umontpellier.fr \\ ${ }^{3}$ Current address: UMR5199 PACEA, Université de Bordeaux, Allée Geoffroy Saint Hilaire (Bat. B8), 33615 Pessac, France
}

Typescript received 5 June 2020; accepted in revised form 17 September 2020

\begin{abstract}
Conodont animals were early jawless vertebrates equipped with a feeding apparatus composed of several tooth-like elements. The P1 elements, at the rear of the apparatus, were characterized by a robust shape and rapid morphological evolution. Occlusion occurred between paired right and left P1 elements, occasioning some bilateral asymmetry, which, together with allometric growth, may partially obliterate the temporal differences. The present study aims to disentangle these different components of morphological variation in Late Devonian Polygnathus P1 conodont elements. An extensive 2D geometric morphometric analysis of the platform shape was performed through the Famennian record of two outcrops. This analysis was completed by a 3D study on a subset of conodont elements. The 2D and 3D morphometric quantifications provided highly congruent results, showing that the $2 \mathrm{D}$ shape constitutes a good approximation of the
\end{abstract}

element geometry. The 3D analysis delivered further insights into the relationship between the geometry of the elements and the constraints related to occlusion. The $2 \mathrm{D}$ analysis allowed a quantitative assessment of the variation among species and through time. Allometry and bilateral asymmetry were differently expressed depending on the species considered, suggesting that constraints imposed on pairing by the morphology of the elements varied even among related species. The within-species variation was so important that it largely obliterated temporal trends; a relationship of Polygnathus shape and conodont biofacies variations through the Famennian nevertheless suggested an evolution driven by ecological interactions between conodont genera.

Key words: conodont, Famennian, bilateral asymmetry, allometry, Polygnathus, occlusion.
A FUnCTIONAL feeding strategy is an evident prerequisite for any growth and survival. Through life history, animals therefore repeatedly evolved buccal tooth-like structures of various shapes and complexity to ensure food comminution. Because of this function in food handling, these elements are mineralized to resist abrasion. They have therefore a good preservation potential in the fossil record. Variations in the geometry of such buccal elements can trace variations in resource exploitation, because different food resources require different functional properties to be efficiently processed (Linde et al. 2004; Price et al. 2011). An ecomorphological approach can thus shed light on the diet of extinct species (Boyer 2008; Gómez Cano et al. 2013). In remote times, such an approach can improve the understanding of past food chains and their variation through time and space
(Purnell et al. 2007). A drawback is that the functional understanding required as a fundament for a valid ecomorphological approach may be more approximate for extinct animals without modern relatives.

Conodonts were small eel-like animals that were important part of the marine fauna from the late Cambrian to the Late Triassic (Briggs et al. 1983; Aldridge et al. 1986, 1993). Isotopic data have recently shown that they were first level consumers (Balter et al. 2019). Conodont animals displayed a complex feeding apparatus, in which the anterior elements formed a structure allowing them to trap food that was further processed by the posterior elements (Aldridge et al. 1987; Purnell \& Donoghue 1997). These buccal elements provide the almost exclusive fossil remains of these former soft-bodied animals to get insights into their palaeobiology, including phylogenetic 
relationships (Donoghue et al. 2000, 2008; Sweet 1988), functional constraints (Donoghue 2001a) and response to environmental changes (Renaud \& Girard 1999; Balter et al. 2008; Girard \& Renaud 2012; Guenser et al. 2019). The buccal elements are most often found isolated, because of the dislocation of the apparatus during fossilization, and because of the procedure of chemical dissolutions most often used to find them in the sediments. Among the different elements composing an apparatus, the platform elements (P1), located at the rear of the conodont mouth, were characterized by a robust shape and rapid morphological evolution that made them useful stratigraphic tools since decades. Their abundance has allowed extensive morphometric studies (Klapper \& Foster 1986; Roopnarine et al. 2004; Jones 2009; Jones et al. 2009; Chen et al. 2016; Hogancamp et al. 2016; Zimmerman et al. 2018; Guenser et al. 2019) shedding light on the morphological variation of many genera. The platform elements of Palmatolepis, Icriodus and Ancyrodella have been shown to vary synchronously according to short-term environmental fluctuations (Renaud \& Girard 1999; Girard \& Renaud 2008). In the latter genus, however, temporal changes are partly masked by allometric variations, constituting an important source of withinspecies morphological variation in several conodont genera (Roopnarine et al. 2004; Chen et al. 2016).

Further, the study of Palmatolepis P1 elements demonstrated a morphological trend from broad to narrow elements through the Famennian (Girard \& Renaud 2012). This period, previously thought to be rather stable, was recently shown to be marked by complex environmental changes interrelating temperature, eustatic and tectonic variations (Girard et al. 2020a). The relative role of these different factors on Palmatolepis evolution is still unclear; furthermore, ecological interactions between the actors of the nektonic fauna, including not only conodonts but also bony fishes and chondrichthyans, rather than abiotic changes per se, could have driven the morphological evolution of buccal elements (Gauchey et al. 2014). The comparison with another conodont record throughout the Famennian may provide elements of choice between the two ranges of hypotheses: an abiotic forcing should cause synchronous changes in different genera. The genus Polygnathus could provide an adequate comparison due to its abundance throughout the period. However, whereas in Palmatolepis right and left platform elements are mirror-images of each other, as expected in bilateral organisms (Lane 1968; Klapper \& Foster 1986; Renaud \& Girard 1999), bilateral asymmetry has been reported in some Polygnathus platform elements (Klapper 1971; Klapper \& Lane 1985). This, together with allometry, may cause an important morphological variability and blur the temporal signal related to environmental or ecological forcing.
In the present study, a landmark-based geometric morphometric approach was used to quantify the shape of Polygnathus P1 elements in two outcrops through which Famennian environmental variations were recently investigated (Girard et al. 2020a), allowing a comparison between morphological variations and the environmental context. Extensive sampling through the Famennian section provided abundant material. For six species, the high number of specimens $(>100)$ allowed a 2D morphometric analysis of temporal variation. The geometry of Polygnathus P1 elements is however characterized by ridges and grooves that are typically three-dimensional structures, suggesting that they could properly be described only using a 3D approach (Martínez-Pérez et al. 2016). A $3 \mathrm{D}$ geometric morphometric analysis was therefore performed on a subset encompassing elements of two species.

The questions investigated were:

1. Could the $2 \mathrm{D}$ description of the platform margin constitute a good approximation of the $3 \mathrm{D}$ geometry of Polygnathus elements? This was assessed by comparing $2 \mathrm{D}$ and $3 \mathrm{D}$ geometric morphometric quantification of a subset of Po. glaber and Po. communis.

2. Is the asymmetry of pairing during occlusion associated with a bilateral asymmetry of the platform shape, suggestive of functional constraints on the element geometry, and conversely, can patterns of bilateral asymmetry in element geometry raise questions about the constraints related to occlusion? Right-left differences in element shape were characterized to address this question.

3. Is the pattern of shape variation conserved across species? This was addressed by assessing the direction of allometric shape changes as well as the balance between allometry and bilateral asymmetry in the different species.

4. Despite the extensive within-group variation, can consistent temporal variations in Polygnathus P1 platform shape be evidenced, and if yes, can a biotic or abiotic candidate factor be identified? A comparison with palaeoenvironmental records from the same outcrops was used to tackle this question.

\section{MATERIAL}

Conodont P1 elements studied here were collected from two outcrops; one in France, (Col des Tribes (CT), Montagne Noire) and one in Germany (Buschteich (BU), Thuringia). During the Late Devonian, both were located in subtropical latitudes, on different microcontinents migrating towards the equator and Laurussia during this period of closure of the Rheic Ocean (Franke et al. 2017). Details regarding their biostratigraphy and 
palaeoenvironments have been presented in recent studies (Girard et al. 2014, 2017). Three proxies derived from the same samples as those considered here were retained for comparison (Girard et al. 2020a): (1) oxygen isotope values provided a palaeotemperature proxy; (2) a scoring of sedimentological facies estimated water depth during deposition; (3) biofacies quantified the changes in the conodont faunas, corresponding to the percentage of the different conodont genera in a sample, including Polygnathus. The percentages were summarized along a main axis using a principal component analysis (PCA).

Both sections delivered a detailed sampling of the Famennian; from the middle to the latest Famennian at BU, and for the whole Famennian at CT. The latest Frasnian was also sampled in the later outcrop (Fig. 1). The stratigraphy was based on Frasnian (Ziegler \& Sandberg 1990) and Famennian (Spalletta et al. 2017) conodont Zones; absolute ages are also provided (Becker et al. 2012).

For each level, all P1 elements of the genus Polygnathus were picked and identified at the species level. The elements with an entire platform were selected for subsequent morphometric analyses. Details of the sampling can be found in Renaud et al. (2020, table 1).

\section{Description of the groups}

Each element is composed of a free blade extending the carina (Fig. 1). Their curvature defines right (dextral) and left (sinistral) elements (sensu Purnell et al. 2000): the free blade being oriented ventrally, left elements have their convex side pointing towards the anterior/rostral direction (Fig. 2). The anterior margin of the platform is located on the convex side and the posterior margin on the concave side of the free-blade-carina curvature. The anterior and posterior platforms tend to display different geometry, further helping in the orientation of the elements, even when the free-blade-carina is almost straight. Right elements were subjected to a horizontal mirror transformation and measured as left elements, so that all could be analysed together.

The elements have been identified to the species level, with the exception of a few undetermined specimens grouped separately for the Frasnian and the Famennian. Some morphologically close species have been related into phylogenetic lineages (Ji \& Ziegler 1993). They were pooled here into these 'phylogenetic groups' in order to improve the sample size and temporal coverage of each taxonomic unit. The same line of argument led to the grouping of the related Polygnathus nodocostatus and Po. semicostatus species into a Po. costatus group. Some species have not been related to any others in phylogenetic lineages, and were considered as group in themselves: Po. aspelundi, Po. brevilaminus, Po. diversus,
Po. lauriformis, Po. margaretae and Po. procerus. The morphological characteristics of the representatives of each group are:

1. aspelundi: Restricted to the Frasnian period. The elements have a high, curved, anterior platform margin and a lower, curved, posterior platform margin. The platform is smooth.

2. brevilaminus: Had a very long stratigraphical range, with both Frasnian and Famennian representatives. The elements are characterized by a small platform, which does not reach the dorsal end. The platform is sub-squared with parallel margins.

3. communis: Includes elements with an elongated, subsymmetrical platform, and without denticles on the lateral margins of the platform.

4. costatus: Includes elements with a large, irregular platform. It pools the nodocostatus species characterized by a regular distribution of nodes on the platform, with nodes parallel to the carina, and the semicostatus specimens which have ridges perpendicular to the carina forming a developed tongue. This group is restricted to the Famennian.

5. decorosus: Typical of the Frasnian. The elements are characterized by a narrow symmetrical and slightly arched platform. Distinct nodes occur at the margins.

6. diversus: Includes elements characterized by an obvious offset between the free-blade and the carina. Two morphotypes exist: one with a massive platform ornamented with nodes, and another one with a platform surface covered by close spike-like denticles.

7. glaber: Elements are characterized by a lanceolate smooth platform. The carina displays pronounced denticles.

8. lauriformis: Elements of this species display a slightly ornamented lanceolate platform resembling a bay leaf.

9. margaretae: Typical of the end Famennian, this species corresponds to very particular guitar-shaped elements.

10. procerus: Elements display a lanceolate, slightly arched platform, and a developed ornamentation.

11. webbi: Elements are characterized by a mildly arched platform with distinct ridges. The blade carries laterally flattened denticles.

A few specimens were left unidentified due to a lack of unambiguous diagnostic characters.

\section{Material 2D and 3D morphometric analyses}

All the elements with an entire platform were selected for the 2D morphometric analysis. In total, 1564 


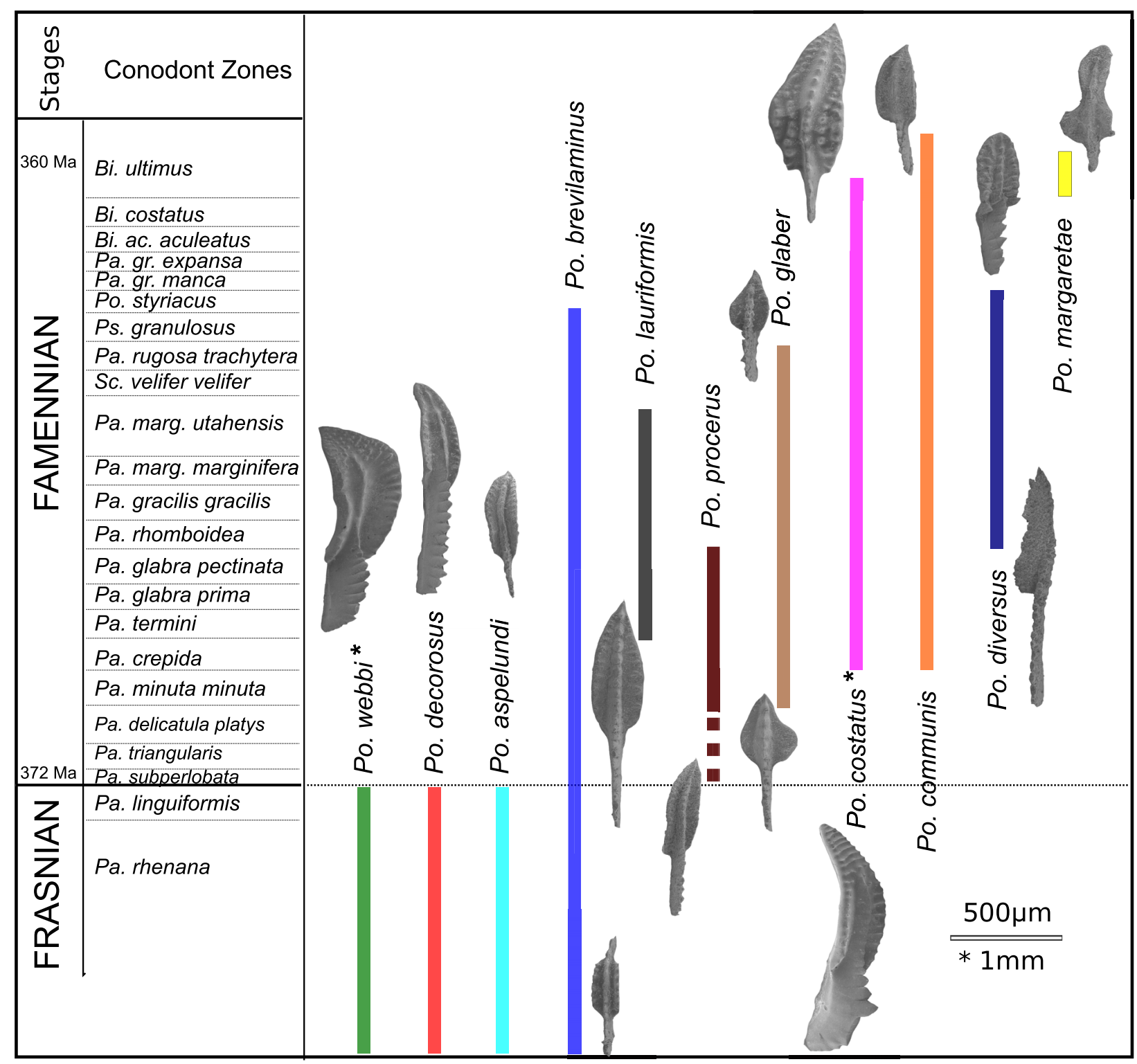

FIG. 1. Temporal distributions of the studied groups of Polygnathus. All specimens to the same scale, except the very large Polygnathus webbi and Po. costatus (denoted by an asterisk). Conodont Zones from Spalletta et al. (2017) for the Famennian and Ziegler \& Sandberg (1990) for the Frasnian. Ages after Becker et al. (2012).

elements were measured. Sample size per section, levels, and taxonomic groups are provided in Renaud et al. (2020).

For the 3D analysis, a set of 34 Polygnathus communis (25 from level CT63 and 9 from CT69) and 30 Po. glaber (all from level BU40) P1 elements were selected to document small and large elements, as well as right and left ones. These species were selected because they were abundant enough to provide $\sim 30$ well-preserved specimens in one or two close levels, to concentrate on within-species variation without interfering temporal variations. The elements were glued onto a toothpick and scanned at a cubic voxel resolution of $1 \mu \mathrm{m}$ using
Phoenix Nanotom $S$ microtomograph $(\mu \mathrm{CT})$ on the AniRA-ImmOs platform of the SFR Biosciences, Ecole Normale Supérieure, Lyon, France. The scanning parameters were as follow: $100 \mathrm{kV}, 70 \mu \mathrm{A}, 3000$ projections at $360^{\circ}$ with no filter. The surface of the element was extracted semi-automatically using the thresholding tool in Avizo (v. 9.1; Visualization Science Group, FEI Company). The 3D models (Po. glaber, Buschteich section: UM BUS 001 to 030; Po. communis, Col des Tribes section: UM CTB 001 to 034) have been deposited in MorphoMuseuM (Girard et al. 2020b). Physical specimens are deposited in the University of Montpellier, France (UM). 
A

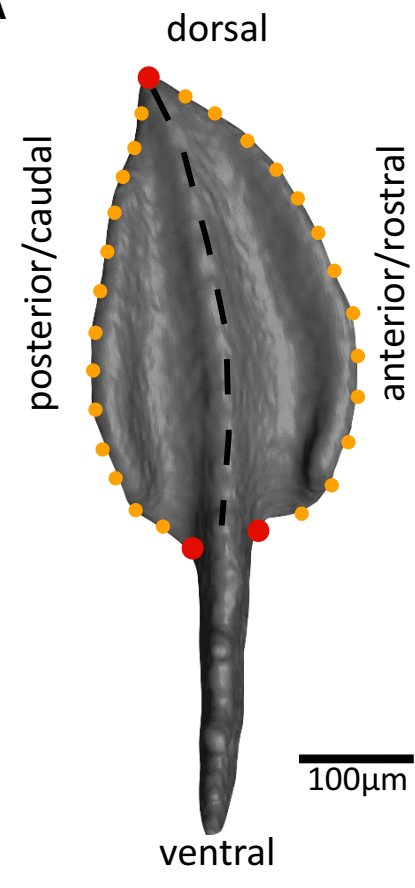

D

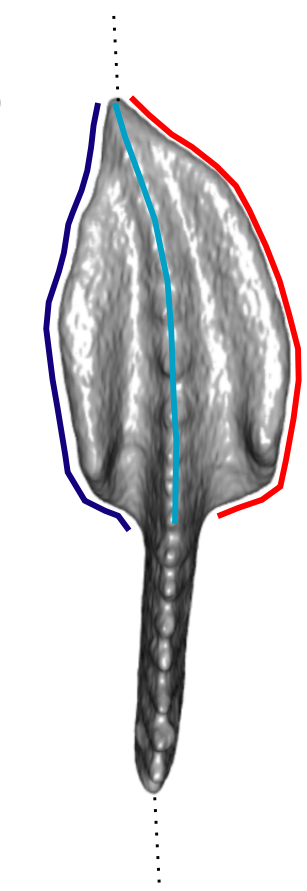

B

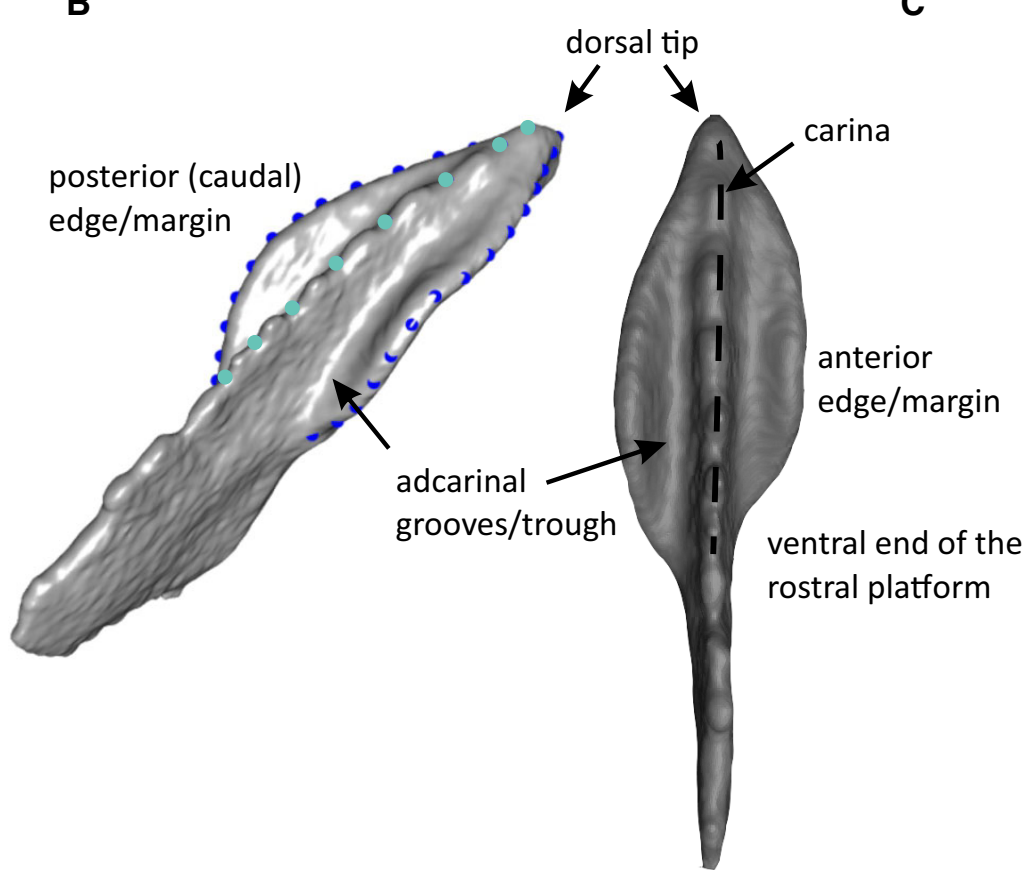

FIG. 2. Location of the $2 \mathrm{D}$ and $3 \mathrm{D}$ landmarks and morphological terms annotated on left P1 Polygnathus elements. A, 2D landmarks (red) and sliding semi-landmarks (orange) on a Po. communis element (level CT63; specimen UM CTB 025). B, 3D landmarks (dark blue) and sliding semi-landmarks (light blue) on a Po. glaber element (level BU40; specimen UM BUS 008). C, additional nomenclature on the occlusal view of the same element. D, orientation of the views used hereafter for visualization, exemplified by a Po. communis element (specimen UM CTB 024 from level CT63). 


\section{METHODS}

Landmarks for the $2 D$ analysis

Each P1 element was glued and pictured with a standard orientation; the oral surface facing the camera. The shape of the platform was quantified in oral view using a set of 3 landmarks and 26 sliding semi-landmarks digitized using TPSDig2 (Rohlf 2010) (Fig. 2). The landmarks described were: (1) the dorsal extremity of the platform; (2) the insertion of the anterior margin of the platform on the free blade; and (3) the insertion of the posterior margin on the free blade (Fig. 2). The two curves of 13 equally distributed sliding semi-landmarks were digitized along the anterior and posterior margins of the platform, from the insertion points to the dorsal extremity of the platform.

\section{Landmarks for the 3D analysis}

The 3 landmarks and 26 sliding semi-landmarks used for the $2 \mathrm{D}$ analysis were manually positioned on the anterior and posterior margins of the 3D surfaces. An additional set of 8 sliding semi-landmarks was registered to document the part of the blade inserted on the platform (carina). These landmarks were positioned in the valleys between the denticles, which are occasionally broken. They were thereafter distributed with a sliding procedure, being anchored between the second landmark, and an additional landmark located on the carina between the insertions of the anterior and posterior margins.

To compare the $2 \mathrm{D}$ and $3 \mathrm{D}$ approaches on the same set of conodonts, the 3D surfaces were manually oriented with the oral surface facing up, so that the orientation of the surface would be similar to the orientation in the 2D acquisition. Snapshots provided 2D images on which the landmarks and semi-landmarks were collected as in $2 \mathrm{D}$.

\section{Procrustes superimposition}

In $2 \mathrm{D}$ and in $3 \mathrm{D}$, the configurations of landmarks and semi-landmarks were superimposed using a generalized Procrustes analysis (GPA) standardizing size, position and orientation while retaining the geometric relationships between specimens (Rohlf \& Slice 1990). During the superimposition, semi-landmarks were allowed to slide along their tangent vectors until their positions minimized the shape difference between specimens, the criterion being the bending energy. The aligned coordinates constituted the shape variables for further analyses. The element size was estimated by the centroid size (CS: square root of the sum of squared distances from the landmarks and semi-landmarks to the centroid).

\section{Analysis of the $3 D$ dataset}

First, a Procrustes superimposition was carried out on a dataset combining Po. communis and Po. glaber. A PCA provided a morphospace visualizing the main pattern of morphological variance.

Second, to investigate whether the $3 \mathrm{D}$ morphometric descriptors could describe the bilateral asymmetry of the elements, separate Procrustes superimpositions were performed for Po. communis and Po. glaber. Differences between right and left elements were analysed using leave-one-out cross-validated linear discriminant analyses (LDA). This procedure removes one specimen at a time, and predicts its classification using LDA functions computed on all the remaining specimens. Classification accuracy is given by the percentage of specimens correctly assigned by the cross-validated LDA (cross-validated percentage, CVP). However, when performing an LDA it is desirable that the number of variables is smaller than the sample size of the smallest group; otherwise, the method tends to provide overoptimistic results (overfitting of the data; Kovarovic et al. 2011; Evin et al. 2013). A reduction of dimensionality can be used to mitigate this issue: a PCA is performed, and only a subset of its axes is retained in the LDA. Looking at the variation of CVP along an increasing number of PC axes included in the LDA can allow an optimization of the reduction of dimensionality (Evin et al. 2013). Such a procedure was employed here because the number of variables greatly exceeded the number of specimens (complete 3D dataset: 37 landmarks, 111 aligned coordinates for $\sim 15$ elements in each group, right or left Po. communis and Po. glaber).

Right/left side and size-related variations in shape and differences between groups were investigated using Procrustes ANOva. With this approach, the Procrustes distances among specimens are used to quantify the components of shape variation, which are statistically evaluated via permutation (here, 9999 permutations; Adams \& Otarola-Castillo 2013). The allometric relationship was visualized as the common allometric component (CAC) derived from an analysis of the aligned coordinates versus size (Adams et al. 2013). In all case, centroid size (CS) was log-transformed to linearize the allometric trends.

The relative importance of the taxonomic attribution, bilateral asymmetry and allometry was further estimated using a multivariate analysis of variance on the reduced dataset, using the ffmanova procedure (Langsrud \& 
Mevik 2012). This method is based on type II sum of squares, which has the advantage of being invariant to ordering of the model terms; the ffmanova also handles colinear responses. It may inflate the percentage of variance explained (pve) but allows an estimation of the relative importance of the explanatory variables.

\section{Comparison of the $2 D$ and $3 D$ datasets}

Three datasets were compared to assess their efficiency in characterizing the different sources of morphological variation: (1) the complete 3D dataset, including the landmarks describing the carina (3Dcar); (2) a reduced $3 \mathrm{D}$ dataset, including only the landmarks also collected for the $2 \mathrm{D}$ analyses along the anterior and posterior margins (3Dmar); (3) the 2D landmarks collected on the snapshots of the 3D surfaces, simplifying the 3D geometry into its $2 \mathrm{D}$ projection (2Dsimp).

The three morphological spaces were compared in a multivariate way using a Protest procedure. This procedure of pairwise comparison provides a coefficient of correlation (ProcR) and a probability that the configurations are more related than random, based on permutations (here, 9999 permutations). The number of PC axes retained in the analyses was determined following the procedure of dimensionality reduction based on LDA performance.

\section{Analysis of the complete $2 D$ dataset}

A first exploration of the total 2D dataset (1564 elements) was performed using a PCA on the aligned coordinates. The sources of morphological variance were further analysed within the six well-sampled taxonomic groups including more than 100 specimens. Allometry was tested in each group using a Procrustes ANOva and its direction was estimated using the CAC. Bilateral asymmetry was tested using LDA and associated CVP. The impact of allometry and asymmetry on the total variation was investigated using linear correlations (Pearson's productmoment correlations) between scores on $\mathrm{PC}_{\text {tot }}$ and $\mathrm{PC} 2_{\text {tot }}$, and scores along CAC (allometry) and canonical variates $(\mathrm{CV})$ characterizing the right/left difference in each taxonomic group.

As in $3 \mathrm{D}$, the relative importance of allometry and asymmetry was further tested using two complementary methods. Procrustes ANOva were performed on the aligned coordinates and ffmanova on the reduced dataset. The model tested was Shape $\sim$ Side $+\log (\mathrm{CS})$.

Patterns of between-group variation were assessed using between-group PCA (bgPCA). This method corresponds to the eigen-analysis of the variance-covariance matrix between group means weighted by the sample size of each group (Culhane et al. 2002; Renaud et al. 2015). Three bgPCAs were performed, considering three different grouping factors, in order to concentrate on different patterns: (1) the taxonomic groups; (2) the levels in each outcrop; (3) the taxonomic groups present in each level. Analyses 2 and 3 allowed us to summarize temporal shape variations along the bgPC1 axes.

Two palaeoenvironmental proxies were considered (Girard et al. 2020a): (1) oxygen isotope values provided a palaeotemperature proxy; (2) biofacies quantified the changes of the conodont faunas. In each level, the percentage of the different conodont genera, including Polygnathus, was assessed; the variation in composition of the assemblages was summarized along the first axis of a PCA of the conodont percentages. In almost all cases, the proxies were measured in exactly the same levels as those included in the morphometric analyses; in few cases, values from bracketed levels were considered instead. These proxies were compared to the Polygnathus shape variations, estimated by scores on the bgPCA axes, using linear (Pearson's product-moment) correlations.

\section{Tools for statistical analyses}

Linear correlations are part of the default statistics in $\mathrm{R}$ ( $\mathrm{R}$ Core Team 2017). The Procrustes superimposition, allometric analysis, and Procrustes ANOva were performed using the R package geomorph (Adams \& Otarola-Castillo 2013). The PCA and bgPCA were performed using ade 4 (Dray \& Dufour 2007). The LDA, with the cross-validated reclassification and the computation of canonical variate axes (CVA), was performed using the package Morpho (Schlager 2017). Note that the term LDA was used for the predictive (inferential) analysis providing cross-validated assignations; and the term CVA for the descriptive approach providing $\mathrm{CV}$ axes on which the individuals were represented. The Protest procedure was implemented in the vegan package (Oksanen et al. 2013) and the ffmanova in the ffmanova package (Langsrud \& Mevik 2012). The original data files as well as details of the statistical results are available in Renaud et al. (2020).

\section{RESULTS}

3D geometry of Po. communis and Po. glaber

The morphometric analysis of the 3D dataset including Po. communis and Po. glaber showed a difference between the two species, opposed along the first axis of the PCA on the aligned coordinates (Fig. 3). A trend existing both 


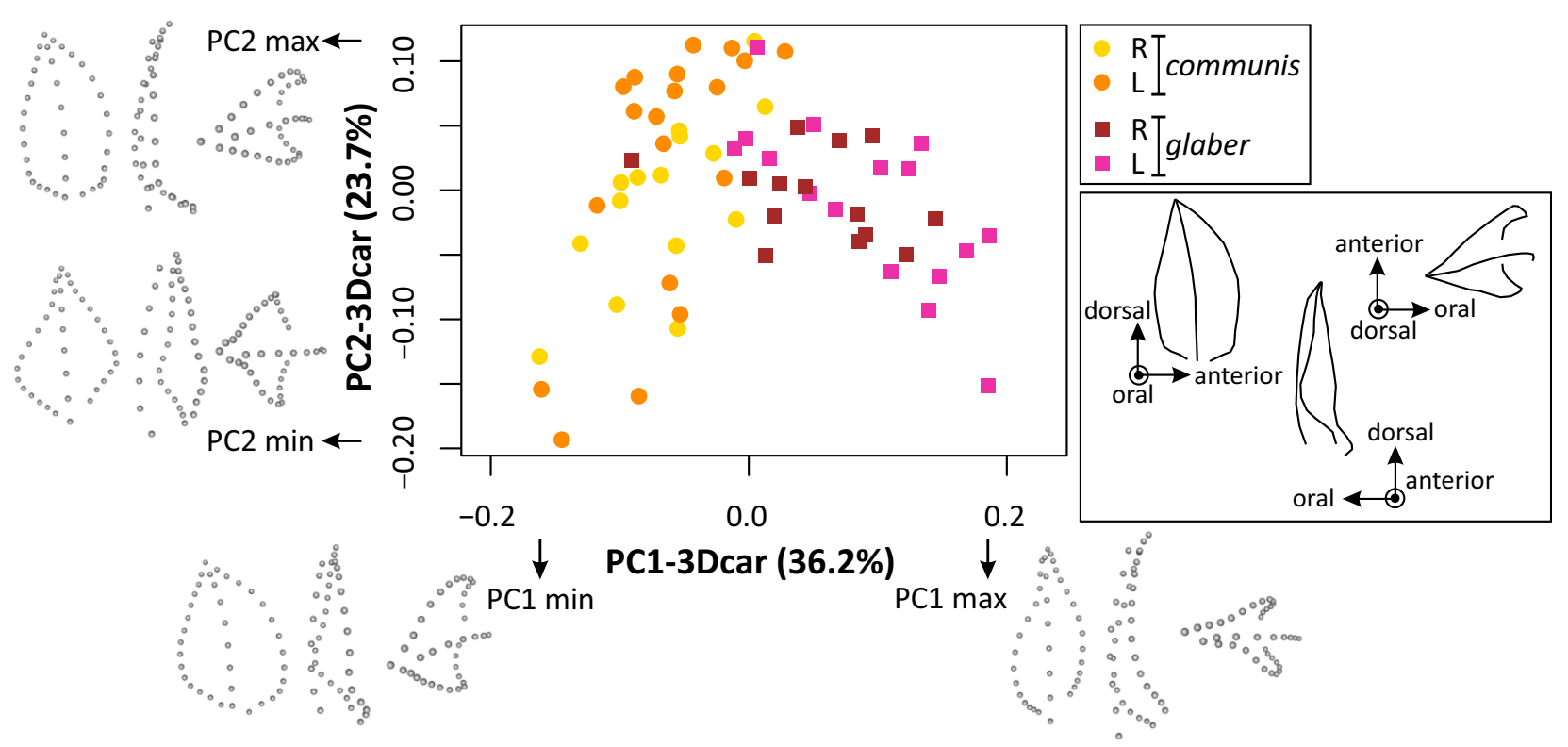

FIG. 3. $3 \mathrm{D}$ morphological variation of Polygnathus communis and Po. glaber. The morphospace corresponds to the first two axes of the PCA on the 3D aligned coordinates, including the sliding semi-landmarks along the carina. Visualizations show the shape at the minimal and maximal scores along the two axes. The orientation of the three views is provided under the legend.

within Po. communis and Po. glaber was displayed along PC2, from relatively wide and flat elements (towards negative scores) to elements with a lanceolate, arched platform with elevated margins delimiting pronounced grooves. This trend is related to size increase (PC2 $\sim \log$ (CS): $\mathrm{R}=0.7284, \mathrm{p}<0.0001)$. Given this relationship with size, small specimens of Po. communis and Po. glaber appeared quite different, rather wide for the former and elongated for the later, whereas large specimens would tend to converge towards a similar lanceolate morphology. For none of the species, right and left elements appeared to segregate in the PCA space.

This relationship with size was further investigated in a multivariate way, using Procrustes ANOVA and the estimation of the CAC for each species separately (Fig. 4). Allometric shape variation was important in Po. communis $(\mathrm{p}=0.0001)$ (Fig. 4A). Small specimens were characterized by relatively flat and wide platforms with slightly elevated margins. In contrast, large specimens are elongated, with elevated margins delimiting deep adcarinal grooves, especially towards the ventral extremity of the platform.

The dispersion around the allometric relationship was more important for Po. glaber $(\mathrm{p}=0.0032)$ (Fig. 4B). Both small and large elements display here a relatively similar lanceolate platform shape, large ones being somewhat wider. The margins of small elements are dorsoventrally relatively flat, whereas they become arch-shaped in large elements. Adcarinal grooves are more pronounced in large elements, being delimited by these elevated margins.

The existence of a right-left asymmetry was explored as a next step using predictive LDA. The issue of overfitting had first to be addressed, because of the number of variables far exceeded the number of specimens. In order to identify the optimal number of PC axes to be retained in the LDA, their number was progressively increased, assessing at each step the percentage of correct cross-validated reclassification of right and left elements (CVP). Note that a $50 \%$ correct classification is expected by chance alone. For both Po. communis and Po. glaber, CVP increases when the number of PC axes increases from two to eight, thereafter reaching a plateau or even decreasing (Fig. 5A). For both species, CVP decreases towards the performance of coin-flipping when the number of PC axes exceeds 25. The LDA were therefore performed, for Po. communis as for Po. glaber, on the first eight PC axes. Even with this procedure optimizing CVP, some Po. communis were wrongly classified (7/34; Fig. 5B) whereas all Po. glaber elements (30 in total) were correctly classified as right or left (Fig. 5C). Differences between right and left elements in Po. communis were therefore tenuous. The anterior margin extended slightly more ventrally and was more elevated in right elements. Conversely, asymmetry in Po. glaber elements involved the ventral extension and elevation of the margins: the posterior margin extends more ventrally and is more elevated in left elements, the reverse being true for right elements. The 
A
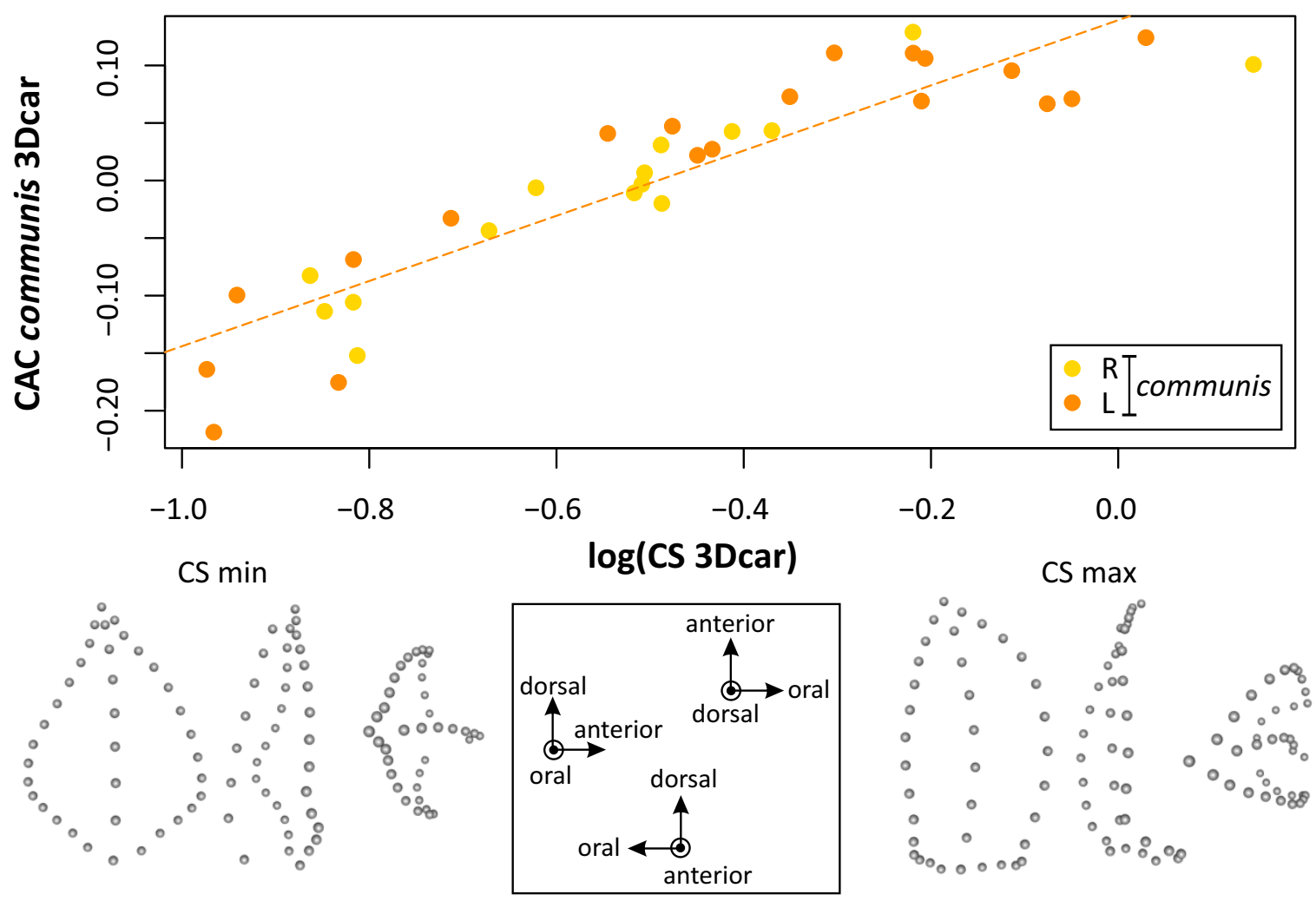

B
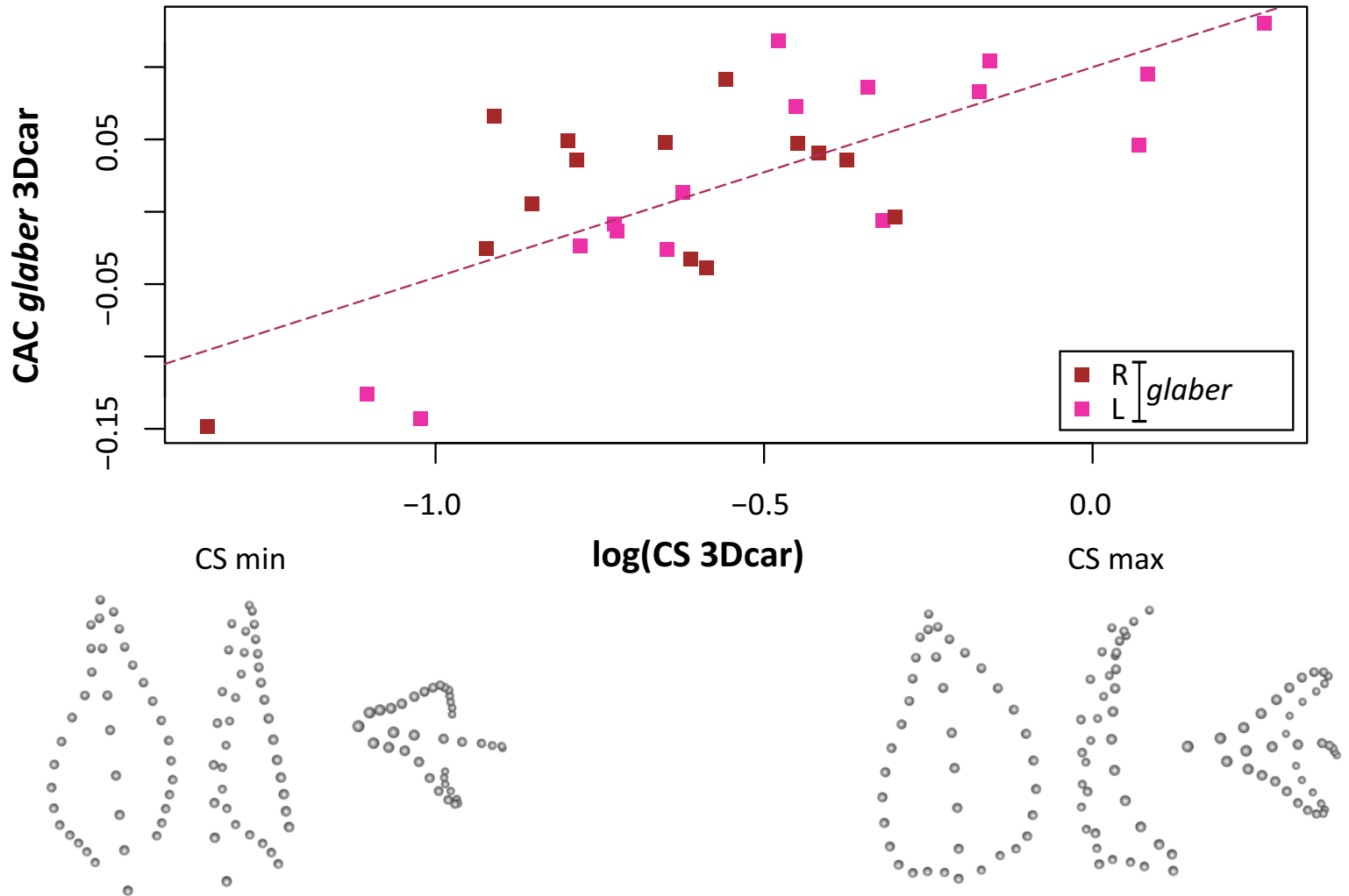

FIG. 4. Allometric relationship within Polygnathus communis (A) and Po. glaber (B). The common allometric component (CAC) summarizes the whole-dimensionality allometric shape variation; it is represented against the logarithm of the centroid size. The shape predicted for the minimum and maximum size is represented for each species. 
visualizations also suggest flatter margins in right elements, but this is also a trait characterizing small elements (see Fig. 4). Large elements were dominantly leftsided, and this may contribute to the morphological difference between right and left Po. glaber and to the good percentage of well-classified elements.

Nevertheless, on a canonical space including as groups right and left elements of both species (Fig. 5D), the asymmetrical difference between right and left elements appeared much less pronounced in Po. communis than in Po. glaber.

Both allometry and asymmetry thus appeared as sources of morphological variation in both species. To assess their relative importance, two-factor Procrustes ANOVA were performed, including side and size (log CS) as factors. When tested in a same model, asymmetry was not significant whereas allometry was highly significant in Po. communis (Side: $\mathrm{p}=0.1423$; Size: $\mathrm{p}=0.0001$ ). In contrast, both asymmetry and allometry were significant in Po. glaber (Side: $\mathrm{p}=0.0139$; Size: $\mathrm{p}=0.0011$ ).

An ffmanova on the reduced dataset (8 PCs) also allowed estimation of the relative percentage of variance explained by each factor. Both allometry and asymmetry were found significant in both species, in contrast with previous results. This is probably due to the reduction of dimensionality, increasing the performance of the tests. In congruence with previous results, however, allometry was the most important factor in Po. communis (Side: pve $=7.9 \%, p=0.0004$; Size: $p v e=11.1 \%, p<0.0001)$ whereas asymmetry was the prominent factor in Po. glaber (Side: $\mathrm{pve}=10.6 \%, \mathrm{p}<0.0001$; Size: $\mathrm{pve}=8.2 \%$, $\mathrm{p}=0.0003)$.
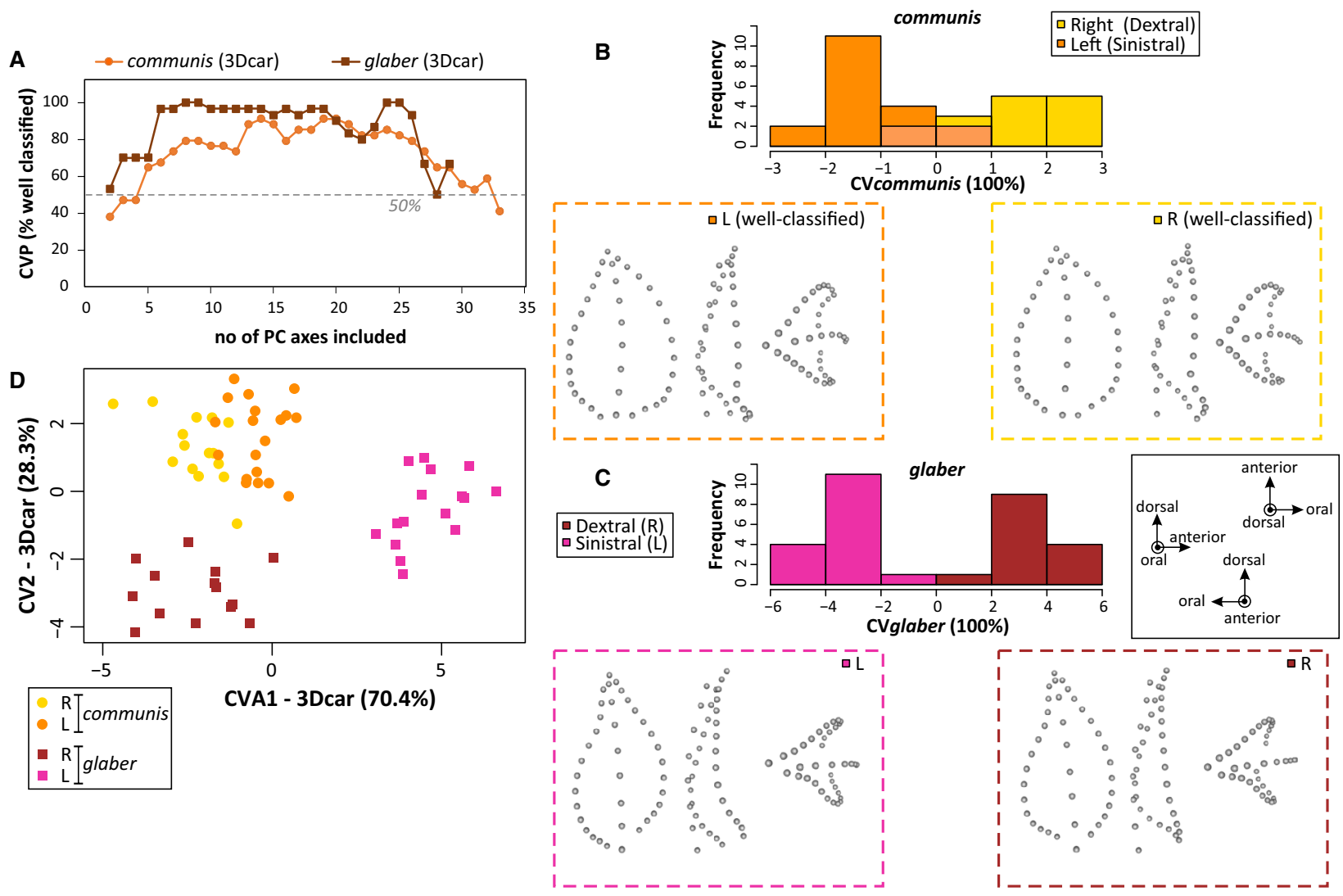

FIG. 5. Predictive linear discriminant analyses between right and left elements of Polygnathus communis and Po. glaber. A, overfitting of the LDA: variation of the cross-validated percentage (CVP) of well-classified elements as a function of the number of PC axes included in the LDA. B, distribution of the scores of right and left elements along the CV axis for Po. communis; below, visualizations of the mean shape of right and left elements; to clarify the morphological difference, only well-classified elements were considered for each group. C, distribution of the scores of right and left elements along the CV axis for Po. glaber; below, visualizations of the mean shape of right and left elements; all elements are well-classified. Note that in B and C, the CV axes represent $100 \%$ of the betweengroup variance, because only one axis discriminates two groups $(\mathrm{R} / \mathrm{L})$. Right elements are represented as mirror images, since they have been measured as left elements. D, morphospace, based on a CVA, showing the differentiation of the right and left elements of the two species. 
Comparison of datasets: $3 D$ with and without carina, and $2 D$ simplification

When discarding the landmarks describing the carina, thus focusing on the platform only, results were highly congruent with those found on the complete configuration including the carina (Protest on the first $8 \mathrm{PCs}$, total sampling: ProcR $=0.9427, \mathrm{p}=0.0001)$. Even the $2 \mathrm{D}$ simplification appeared to provide a very close approximation of the results based on the $3 \mathrm{D}$ geometry, when focusing on the platform margins as in 2D (Protest, 3Dmar/2Dsimp: ProcR $=0.8112, \mathrm{p}=0.0001$ ) or even when including the carina (Protest, 3Dcar/2Dsimp: ProcR $=0.7822, \mathrm{p}=0.0001)$.

The similarity of $3 \mathrm{D}$ results with or without the carina hold true when considering Po. communis alone (3Dcar/ 3Dmar: ProcR $=0.9251, \mathrm{p}=0.0001$ ) and Po. glaber alone (3Dcar/3Dmar: ProcR $=0.8075, \mathrm{p}=0.0001$ ). The good approximation of the $2 \mathrm{D}$ compared with $3 \mathrm{D}$ results is also confirmed for the two species, when considering the 3D description with the carina (Po. communis, 3Dcar/ 2Dsimp: ProcR $=0.7901, \mathrm{p}=0.0001 ;$ Po. glaber, 3Dcar/ 2Dsimp: ProcR $=0.7114, \mathrm{p}=0.0001$ ) and without the carina (Po. communis, 3Dmar/2Dsimp: ProcR $=0.8065$, $\mathrm{p}=0.0001 ;$ Po. glaber, 3Dmar/2Dsimp: Prock $=0.7818$, $\mathrm{p}=0.0001)$.

\section{Analysis of the total 2D dataset}

Pattern of total variance. When considering all Polygnathus P1 elements present in the assemblages from the late Frasnian to the end Famennian, the variation in the morphospace summarized by the first two axes of a PCA on the aligned coordinates (Fig. 6A) presents a Tshape meaning that groups highly variable along $\mathrm{PC} 1$ are not variable along $\mathrm{PC} 2$, and vice versa. The first axis (45.1\% of total variance) corresponds to a deformation leading from elements with a ventrally extended posterior margin to elements with a ventrally extended anterior margin. A further difference in the shape is involved: towards negative scores, the margins are more curved, especially the posterior one, leading to a dropshaped platform. In contrast, towards positive scores, the platform displays a slender, lanceolate shape with a sharp dorsal extremity.

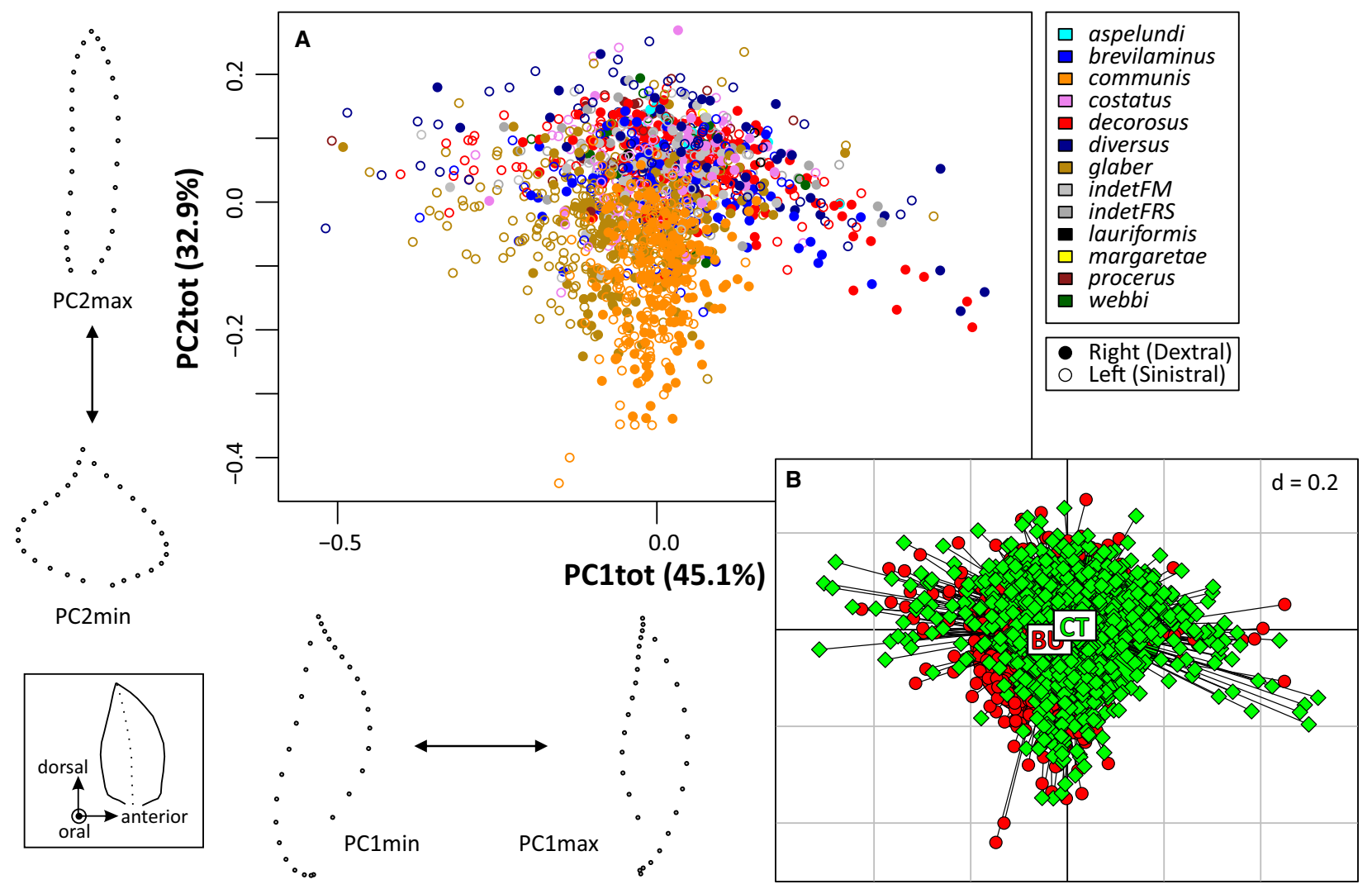

FIG. 6. Morphospace corresponding to the $2 \mathrm{D}$ analysis of the platform shape in the total sample. The first two axes of a PCA on the aligned coordinates are represented, with visualization of the shapes corresponding to extreme scores along the axes. A, representation of the taxonomic units (colours); symbols correspond to the side (dextral (right)/sinistral (left)). B, same axes, with representation as a function of the section (green diamonds, CT; red circles, BU). 

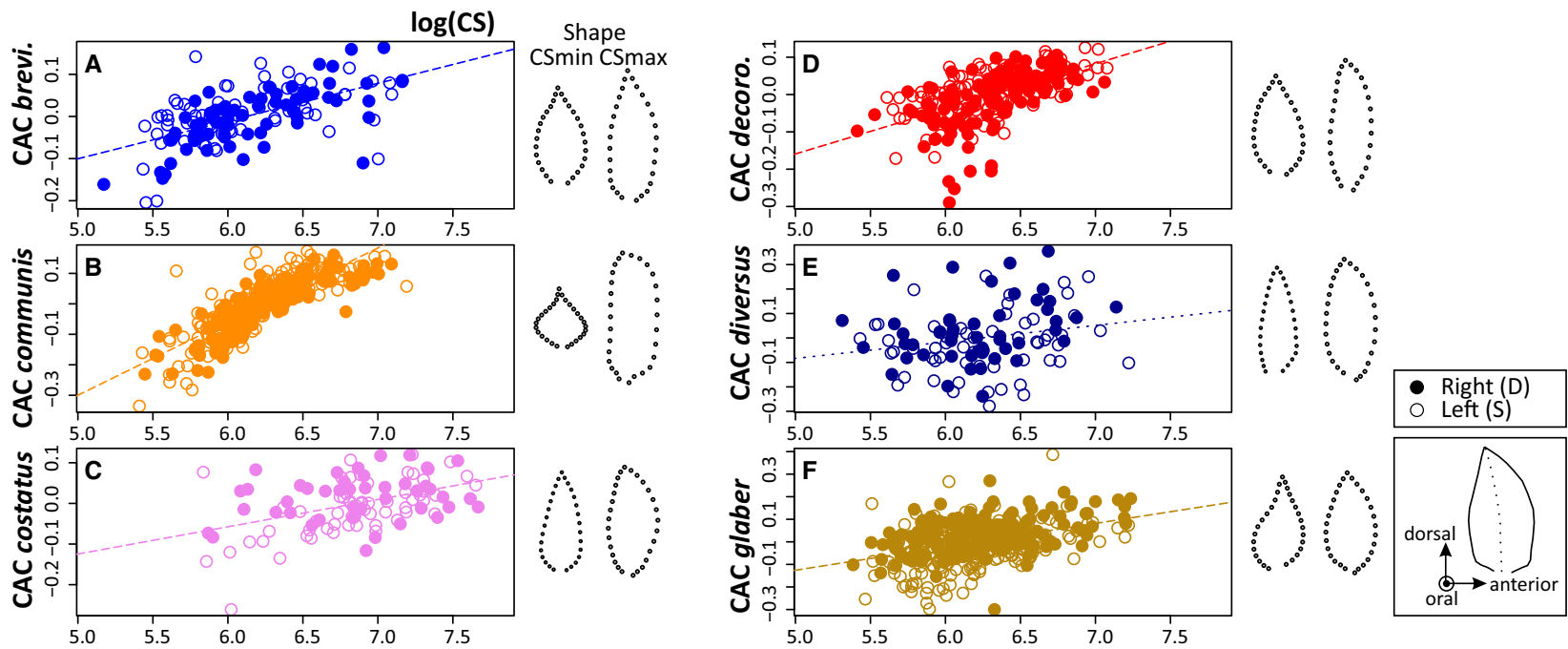

FIG. 7. Relationship between size and shape in the six well-sampled taxonomic groups. Log(centroid size) is shown vs scores for the common allometric component computed for each taxonomic group. The dotted line represents the regression between the two variables. The linear regression was significant in all cases $(\mathrm{p}<0.01$ except for Polygnathus diversus, $\mathrm{p}<0.05)$. The shapes predicted for the minimum and maximum $\log (\mathrm{CS})$ are represented. A, Po. brevilaminus. B, Po. communis. C, Po. costatus. D, Po. decorosus.

E, Po. diversus. F, Po. glaber.

The different taxonomic groups do not segregate along this axis, which rather corresponds to a within-group variance shared by several groups, especially Po. decorosus and Po. diversus. Left (sinistral) elements tend to display negative scores more frequently, whereas right (dextral) elements tend to plot towards positive values; however, an extensive overlap between right and left elements exists. The scores of most genera are centred around zero, except for Po. glaber whose distribution is shifted towards negative scores.

A taxonomic signal is more apparent along the second axis (PC2 total, 32.9\%), opposing elements with very elongated platforms to heart-shaped elements mostly characterizing Po. communis and Po. glaber.

The elements from the two outcrops overall share the same zone in the morphospace (Fig. 6B), although the sample from the Buschteich section (BU) is slightly shifted towards negative PC1 scores. This is attributable to a larger abundance of Po. glaber in BU than in CT (Famennian alone: Po. glaber $=48 \%$ of the assemblage in BU and 22\% in CT; see Renaud et al. 2020, table 1), this species typically plotting within this zone of the morphospace.

The T-shaped structure of the PCA morphospace may be due to a complex balance between bilateral asymmetry and allometry, previously addressed in the 3D morphometric analysis. The two sources of morphological variation were therefore further explored in the six wellsampled groups: Polygnathus brevilaminus, Po. communis, Po. costatus, Po. decorosus, Po. diversus and Po. glaber; all represented by more than 100 specimens.
Allometry. Shape was highly related to size in Po. brevilaminus, Po. communis, Po. decorosus and Po. glaber (Procrustes ANOVA, aligned coordinates $\sim \log (\mathrm{CS}): \mathrm{p}=0.0001)$, moderately in Po. costatus $(\mathrm{p}=0.0086)$ and not significantly in Po. diversus $(\mathrm{p}=0.2404)$. The CAC provided a synthetic visualization of the relationship (Fig. 7). In the case of the five significant multivariate relationships, the shape associated with a large size corresponded to a typical Polygnathus platform shape, elongated but with a more or less rectangular (Po. communis) or sharp (Po. brevilaminus) dorsal edge. However, the small elements differed markedly, with a heart-shaped platform in Po. communis (Fig. 7B), lanceolate platform in Po. costatus (Fig. 7C) and drop-shaped platform in Po. glaber (Fig. 7F). This resulted in a different relationship between the allometric variation and the axes of the total PCA (Table 1). In Po. brevilaminus, Po. communis and Po. decorosus, the allometric signal was tightly related to the variations along PC2, leading from heart-shaped to elongated platforms (CAC vs PC2 total: R $>0.9, \mathrm{p}<0.0001$ ). In contrast, in Po. glaber the allometric signal was mostly expressed along PC1. This explained the distribution of this group along PC1 total (Fig. 6A): the elements displaying negative PC1 scores corresponded to small, drop-shaped platforms. In Po. diversus, the allometric signal expressed by the CAC was also strongly related to PC1 $(\mathrm{R}=0.9385)$, although the multivariate relationship failed to be significant. A similar relationship existed in Po. costatus, although the relationship was less tight $(\mathrm{R}=0.6254)$.

Asymmetry. For each taxonomic group, an LDA was performed on the aligned coordinates to discriminate the 
TAB LE 1. Relationship between total variation, allometry and bilateral asymmetry.

\begin{tabular}{|c|c|c|c|c|c|c|c|}
\hline & \multicolumn{4}{|c|}{ Allometry } & \multicolumn{3}{|c|}{ Asymmetry } \\
\hline & \multicolumn{2}{|c|}{ CAC/PC1tot } & \multicolumn{2}{|c|}{ CAC/PC2tot } & \multirow{2}{*}{$\begin{array}{l}\text { LDA } \\
\text { CVP }\end{array}$} & \multicolumn{2}{|c|}{ CV R-L/PC1 tot } \\
\hline & $\mathrm{R}$ & p-value & $\mathrm{R}$ & p-value & & $\mathrm{R}$ & p-value \\
\hline brevilaminus & 0.1769 & 0.0368 & 0.9113 & $<2.2 \times 10^{-16}$ & $60 \%$ & 0.2071 & 0.0141 \\
\hline communis & 0.1494 & 0.0055 & $\overline{0.9937}$ & $<2.2 \times 10^{-16}$ & $71 \%$ & 0.4518 & $<2.2 \times 10^{-16}$ \\
\hline costatus & 0.6254 & $9.87 \times 10^{-13}$ & $\overline{0.2959}$ & 0.0022 & $58 \%$ & 0.4319 & $4.23 \times 10^{-6}$ \\
\hline decorosus & 0.5898 & $<2.2 \times 10^{-16}$ & 0.9887 & $<2.2 \times 10^{-16}$ & $71 \%$ & 0.3645 & $3.30 \times 10^{-9}$ \\
\hline diversus & $\underline{0.9385}$ & $<2.2 \times 10^{-16}$ & $\overline{0.7016}$ & $<2.2 \times 10^{-16}$ & $48 \%$ & 0.3043 & 0.0015 \\
\hline glaber & $\overline{0.9666}$ & $<2.2 \times 10^{-16}$ & 0.1418 & 0.0057 & $82 \%$ & 0.4749 & $<2.2 \times 10^{-16}$ \\
\hline
\end{tabular}

CAC, common allometry component; CV R-L, canonical variate discriminating right and left specimens; CVP, percentage of well-classified specimens using cross-validation; LDA, linear discriminant analysis between right and left specimens; PC1tot, PC2tot, first and second axes of PCA total. Pearson coefficient of correlation and p-values: $\mathrm{p}<0.0001$ in bold; $\mathrm{p}<0.05$ italic; $\mathrm{R}>0.9$ underlined.

right and left elements. This analysis provided the percentage of specimens correctly assigned by cross-validation (CVP), and scores of the specimens along the discriminant axis (or canonical variate, CV) (Fig. 8). The best CVP was obtained for Po. glaber (CVP $=82 \%)$. The discrimination was still good for Po. communis and $P o$. decorosus $(\mathrm{CVP}=71 \%)$. For Po. brevilaminus and Po. costatus, it was hardly better than coin-flipping (CVP brevilaminus $=60 \%$, CVP costatus $=58 \%)$. For Po. diversus, it was even worse than coin-flipping, with $<50 \%$ of wellclassified specimens $(\mathrm{CVP}=48 \%)$.

In all cases, the right element tended to display an anterior margin that extended more ventrally than the posterior margin. The left elements either displayed both margins extending to the same level, or a posterior margin extending more ventrally in Po. glaber. For the six taxonomic groups, the scores of the specimens along the $\mathrm{CV}$ axis discriminating right and left specimens were significantly correlated, with scores on PC1 total (Table 1; Fig. 8). The correlation was high for Po. communis, Po. costatus and Po. glaber $(\mathrm{R}>0.4)$, moderate for Po. decorosus and Po. diversus $(0.3<\mathrm{R}<0.4)$ and low in Po. brevilaminus $(\mathrm{R}<0.3)$.

Relative balance between asymmetry and allometry. Obviously, the importance of allometry and asymmetry varied across the taxonomic groups. To better evaluate their relative importance, two complementary methods were applied. First, Procrustes anovas were performed on the aligned coordinates, with Side (right/left) and $\log (\mathrm{CS})$ as factors. Second, ffmanova were performed with the same explanatory factors, but on a reduced dataset, retaining the first 8 PCs as for the 3D approach.

Overall, both methods provided congruent results (Table 2). Both allometry and bilateral asymmetry were important factors in Po. communis, Po. decorosus and Po. glaber. These were the three taxonomic groups with the highest CVP provided by the discriminant analyses, but asymmetry never explained more than $5 \%$ of variance. In contrast, allometry explained almost $10 \%$ of shape variance in Po. decorosus, and more than $15 \%$ in Po. communis. The situation was more balanced in Po. glaber. Both allometry and asymmetry were significant in Po. costatus, but each explaining less than $6 \%$ of variance. Only allometry was significant in Po. brevilaminus. In Po. diversus, both factors explained less than $3 \%$ of variance; this explained incongruent results between the two methods.

\section{Analysis of the differentiation between taxonomic groups}

The previous results show that the within-group variation is extensive in Polygnathus. Furthermore, the components of shape variance that are involved vary depending on the taxonomic group. Allometry may be very important (e.g. Po. communis) or only marginally significant (Po. diversus). The allometric variation further differs from group to group, leading from heart-shaped to rectangular platforms in Po. communis or from drop-shaped to lanceolate platform in Po. glaber. As a consequence, allometry was expressed on the second or the first axis of total variance, respectively. As for bilateral asymmetry (right/left differences), its amount varied across groups, but it was always more or less expressed on PC1 total.

Consequently, the total PCA failed to express consistent pattern of taxonomic differentiation, being overwhelmingly impacted by within-group variance. A between-group PCA was thus applied to concentrate on the pattern of between-group variance (Fig. 9). The taxonomic grouping contributed for $21.9 \%$ of the total variance. The first and second axes explained together more than $90 \%$ of variance. Groups with a broad platform (heart-shaped for Po. communis and drop-shaped 

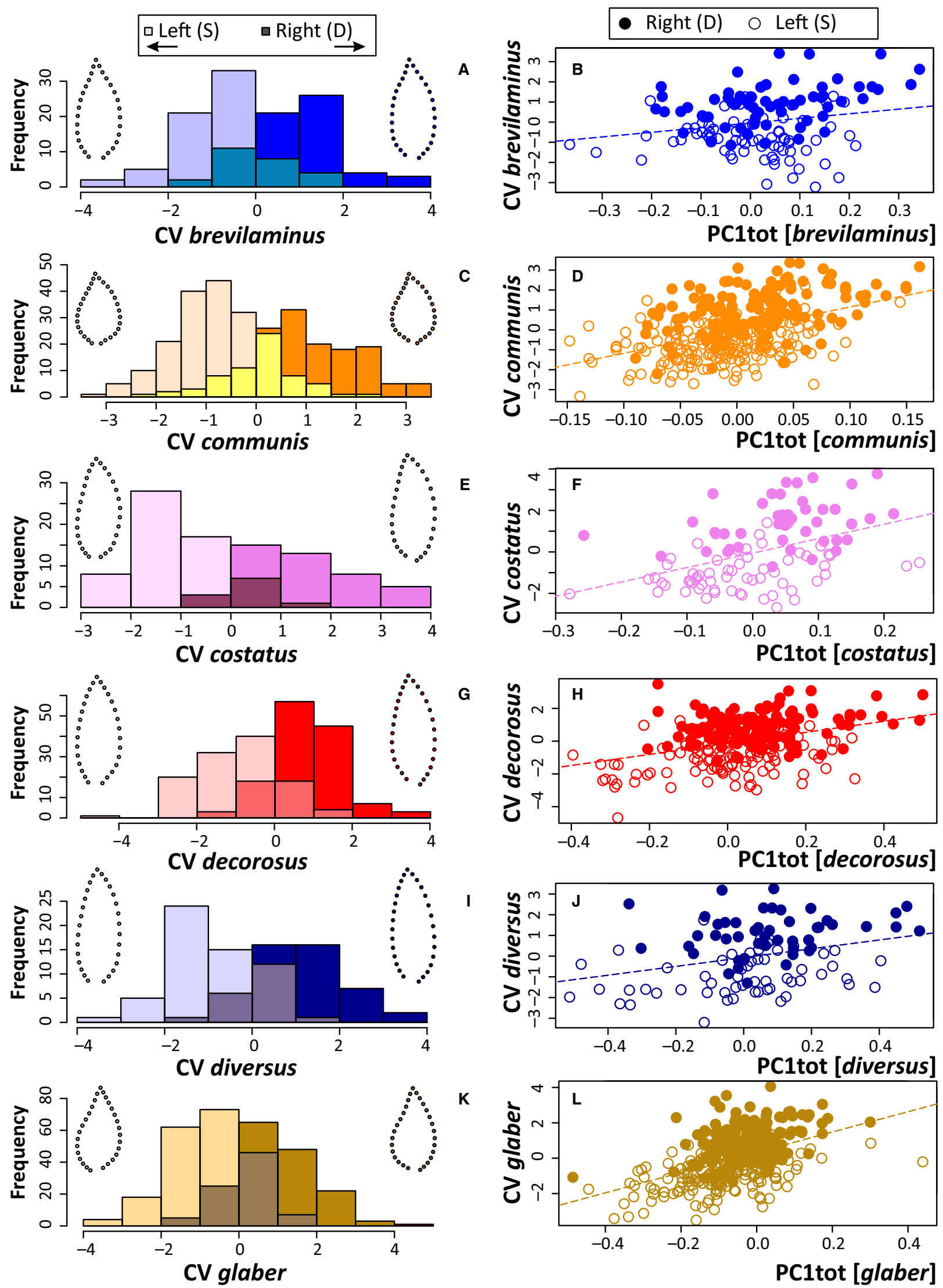
TAB LE 2. Relative importance of allometry and bilateral asymmetry on Polygnathus shape in the six well-sampled taxonomic groups.

\begin{tabular}{|c|c|c|c|c|c|c|}
\hline & \multicolumn{2}{|l|}{ procD.lm } & \multicolumn{4}{|c|}{ ffmanova } \\
\hline & \multirow{2}{*}{$\begin{array}{l}\text { Side } \\
\text { p-value }\end{array}$} & \multirow{2}{*}{$\begin{array}{l}\log (\mathrm{CS}) \\
\text { p-value }\end{array}$} & \multicolumn{2}{|l|}{ Side } & \multicolumn{2}{|c|}{$\log (\mathrm{CS})$} \\
\hline & & & pve & p-value & pve & p-value \\
\hline brevilaminus & 0.1103 & 0.0001 & $1.2 \%$ & 0.117 & $7.7 \%$ & $8.39 \times 10^{-15}$ \\
\hline communis & $<0.0001$ & 0.0001 & $3.1 \%$ & $<2.2 \times 10^{-16}$ & $17.1 \%$ & $<2.2 \times 10^{-16}$ \\
\hline costatus & 0.0009 & 0.0050 & $2.3 \%$ & 0.0045 & $5.3 \%$ & $6.79 \times 10^{-7}$ \\
\hline decorosus & $<0.0001$ & 0.0001 & $4.3 \%$ & $1.12 \times 10^{-13}$ & $9.5 \%$ & $<2.2 \times 10^{-16}$ \\
\hline diversus & 0.0322 & 0.1894 & $1.2 \%$ & 0.3558 & $3.0 \%$ & 0.00096 \\
\hline glaber & $<0.0001$ & 0.0001 & $3.9 \%$ & $<2.2 \times 10^{-16}$ & $7.0 \%$ & $<2.2 \times 10^{-16}$ \\
\hline
\end{tabular}

The significance of side (right-left) and size $(\log (\mathrm{CS}))$ on the aligned co-ordinates was estimated using a Procrustes ANOVA, using 9999 permutations. The percentage of variance and significance of the same factors was also estimated on the first 8 PCs of the PCA total using a ffmanova. CS, centroid size; pve, percentage of variance explained; $\mathrm{p}<0.001$ in bold; $\mathrm{p}<0.05$ in italic.

for Po. glaber) were opposed to groups with an elongated platform, a pattern expressed on the second axis of the PCA. Note that the differentiation of groups with peculiar shape, such as Po. margaretae, does not drive the first axes of the bgPCA, because of their poor representation in the total sample.

\section{Analysis of the temporal variation}

Between-group PCA thus appears as a way to mitigate the issue of the extensive within-group variation, blurring taxonomic and temporal patterns of variation. Two further bgPCAs were performed, to deliver relevant scores along axes summarizing the between-group variation.

Temporal variation of the Polygnathus assemblage. A between-group PCA was performed with the levels through the two $\mathrm{BU}$ and $\mathrm{CT}$ sections as a grouping factor, explaining $27 \%$ of the total shape variance. The scores along bgPC1 (61.7\% of between-group variance) were highly correlated to the scores along PC2tot $(\mathrm{R}=-0.9556, \mathrm{p}<0.0001)$. This axis thus corresponds to the same morphological change, opposing elongated to heart-shaped platforms. Both sections display overall similar records (Fig. 10A). Elongated shapes dominated until $\sim 365 \mathrm{Ma}$, switching towards heart-shaped Polygnathus during the late Famennian. These variations correspond to mean shape changes of the assemblage present in each level, and hence mostly traduce taxonomic replacement.

This aspect was addressed with a second between-group PCA, the grouping variable being each taxonomic group per level. This grouping explained $41.3 \%$ of the total variance. The first axis (55.9\% of between-group variance) opposed late Frasnian and most Famennian groups (Fig. 10B), all sharing an elongated platform shape, to Po. communis which almost exclusively composed the assemblages towards the end of the Famennian record. The disappearance of the elongated Po. brevilaminus towards $365 \mathrm{Ma}$, replaced by the heart-shaped Po. communis, mostly explains the shift in the assemblage mean shape. However, temporal variation also exists within some taxonomic groups: Po. costatus and Po. glaber shifted towards wider platform shape before the rise of Po. communis.

These shape variations were related to palaeoenvironmental proxies, due to concomitant temporal trends. The assemblage mean shape was significantly correlated to conodont biofacies (Table 3). Considering the shape variations within the well-sampled taxonomic groups, Po. communis also displayed a significant correlation with conodont biofacies. In contrast, Po. brevilaminus shape variation was correlated with the palaeotemperature record. Polygnathus costatus was related to both conodont biofacies and palaeotemperature.

FIG. 8. Bilateral asymmetry in the six well-sampled taxonomic groups, and relationship with the first axis of total variance. A, C, E, G, I, K, distribution of the scores of right and left elements along the CV axis computed for each taxonomic group. B, D, F, H, J, L, relationship between the scores on PC1tot (see Fig. 6) with the scores on the CV axis computed for each taxonomic group. Filled circles, dextral (right) elements; open circles, sinistral (left) elements. Note that PC1tot is the same axis on all panels, with different scales corresponding to the range of variation of each taxonomic group. The dotted line represents the regression between the two variables; it is significant in all cases. A-B, Polygnathus brevilaminus. C-D, Po. communis. E-F, Po. costatus. G-H, Po. decorosus. IJ, Po. diversus. K-L, Po. glaber. 


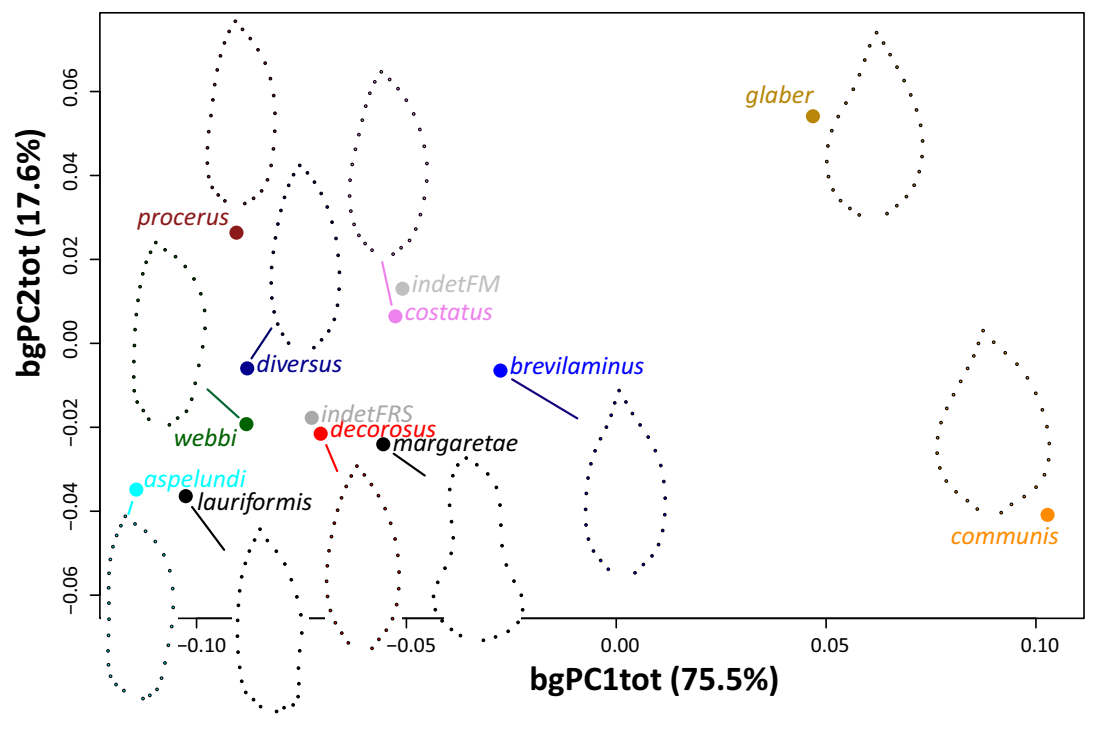

FIG. 9. Platform shape differentiation between the taxonomic groups in a morphospace defined by the first two axes of a betweengroup PCA on the aligned coordinates. Dots correspond to group means, with the same colour code as Figure 1. A visualization of mean shape is shown close to the corresponding dot.

\section{DISCUSSION}

$2 D$ analysis as a good proxy of $3 D$ shape for investigating shape variation

Polygnathus P1 elements are characterized by a complex three-dimensional structure, with elevated margins delineating grooves. Studying the two-dimensional projection thus seems to be a coarse simplification that may miss many morphological features of functional relevance. A comparative study of the same conodonts was therefore performed in $2 \mathrm{D}$ and $3 \mathrm{D}$ with surprisingly highly congruent results. This suggests that any change in the threedimensional geometry also has a signature on the twodimensional projection of the platform. Such results support the use of 2D analyses, so closely echoing 3D approaches, as valuable tools to investigate the evolution of Polygnathus. By allowing extensive sampling, 2D approaches could allow both a good temporal coverage and the assessment of intraspecific sources of morphological variance. However, on reduced subsampling, the 3D analysis provided a more detailed assessment of the geometry of the elements, especially useful for investigating their functional consequences.

Tridimensional geometry and constraints on the interlocking of the elements

The geometry of the right and left elements necessarily impacted the way they interlocked during occlusion. Based on several clusters, including some belonging to Polygnathus, it is admitted that the blade of the left element came behind the blade of the right element in complex conodonts (Donoghue \& Purnell 1999; Martínez-Pérez et al. 2016). In Idiognathodus (Donoghue \& Purnell 1999), the carina does not extend far on the platform, involving a morphology where interlocking relied mostly on the central groove and its ornamentation (Fig. 11A). The presence of a carina in Polygnathus requires, in contrast, a groove to insert it and stabilize the rotational movement during occlusion (MartínezPérez et al. 2016). The right blade thus inserted into the anterior adcarinal groove of the left element, and the left blade into the posterior groove of the right element (Fig. 11B). This morphology suggests that the 'principal point of articulation' was the ventral end of the posterior platforms, because a more excavated adcarinal trough guides the margin of the right element (Martínez-Pérez et al. 2016). To accommodate this interlocking, the ventral extension of the posterior margin is less on the right than on the left side, leading to a marked offset between the extension of the anterior and posterior margins on the right element (Fig. 11B) (Martínez-Pérez et al. 2016). The ventral extension of the margin seems thus related to its role in delineating a more or less deep groove.

A comparison of the Idiognathodus and Polygnathus xylus clusters already shows that the ventral extension of the margins could considerably vary. The posterior margins extend more ventrally on the right and left elements in Idiognathodus whereas the anterior margins tend to extend more ventrally in Po. xylus; the offset is however more pronounced in the right element, leading to a bilateral asymmetry of the elements. As already mentioned, however, interlocking functioned differently in these two genera, because of the presence or absence of a developed carina on the platform. 
Polygnathus Shape

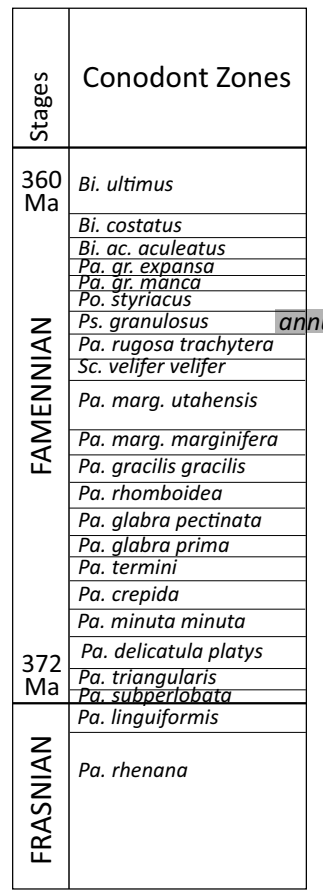

A bgPC1level

(61.7\%)
B bgPC1level+groups

(55.9\%)

$\begin{array}{lllll}0.2 & 0.1 & 0.0 & -0.1 & -0.2\end{array}$

$\begin{array}{lllll}0.2 & 0.1 & 0.0 & -0.1 & -0.2\end{array}$

$\begin{array}{llll}0.20 & 0.10 & 0.00 & -0.10\end{array}$

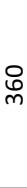

음-

ulata -
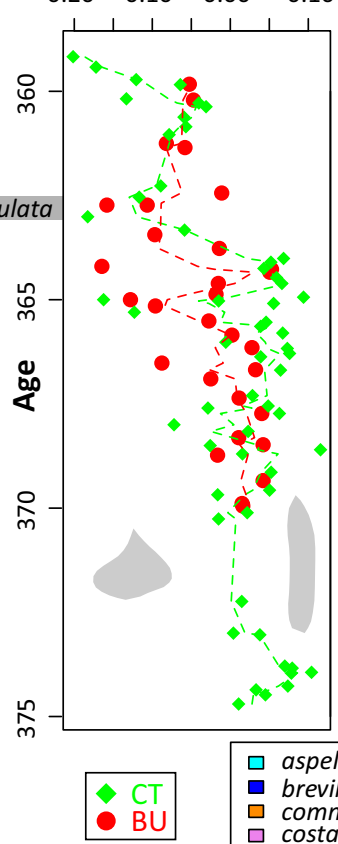

$+1$

$\square$ aspelund

- brevilaminus

$\square$ communis
$\square$ costatus
Environmental Proxies

\section{Conodont Biofacies (PC1)}

$\begin{array}{llll}-80 & -40 & 0 & 20\end{array}$

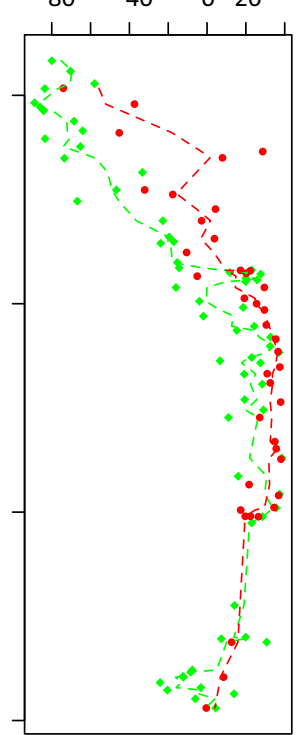

$-$

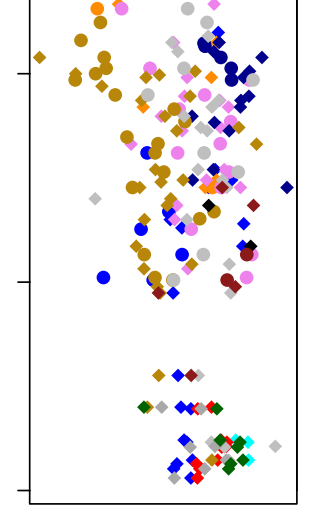

口 decorosus lauriformis

- diversus $\square$ margaretae

glaber $\square$ procerus
$\square$ indetFM $\quad$ webbi

$\square$ indetFRS

FIG. 10. Temporal variation of Polygnathus shape and palaeoenvironmental proxies through the late Frasnian and the Famennian. A, variation in mean shape of the Polygnathus assemblage at each level of the BU and CT sections, estimated by scores on the first axis of a bgPCA on the aligned coordinates, the grouping variable being the level from which the conodonts were picked; shapes corresponding to minimum and maximum scores illustrate the morphological variation involved; dashed lines indicate 3-points moving average. B, temporal variation in mean shape of the Polygnathus taxonomic groups; the scores on the first axis of a bgPCA are represented, the grouping variable being here the taxonomic group per level. C, variations of conodont biofacies, depicted as scores along the first axis of a PCA on the percentages of the different conodont genera; dashed lines indicate 3-points moving average.

$\mathrm{D}$, palaeotemperature record, estimated by oxygen isotope values measured in conodont apatite; dotted lines join the successive values. C and D after Girard et al. (2020a).

TABLE 3. Correlation between the temporal variations in Polygnathus shape and two palaeoenvironmental proxies: oxygen isotope values from conodont apatite and conodont biofacies.

\begin{tabular}{|c|c|c|c|c|c|c|}
\hline & \multicolumn{3}{|c|}{$\partial^{18} \mathrm{O}$} & \multicolumn{3}{|c|}{ Biofacies } \\
\hline & $\mathrm{N}$ & $\mathrm{R}$ & p-value & $\mathrm{N}$ & $\mathrm{R}$ & p-value \\
\hline bgPC1/level & 41 & 0.3273 & 0.0367 & 79 & -0.4582 & $2.17 \times 10^{-5}$ \\
\hline \multicolumn{7}{|c|}{ bgPC1/level + species } \\
\hline brevilaminus & 16 & -0.7965 & 0.0002 & 22 & 0.3821 & 0.0793 \\
\hline communis & 12 & 0.4222 & 0.1716 & 27 & -0.4874 & 0.0099 \\
\hline costatus & 22 & 0.5777 & 0.0049 & 30 & -0.5157 & 0.0035 \\
\hline diversus & 11 & 0.3007 & 0.3688 & 19 & 0.4021 & 0.0880 \\
\hline glaber & 26 & -0.0775 & 0.7066 & 40 & -0.2007 & 0.2142 \\
\hline
\end{tabular}

Mean shape per level was estimated for the whole Polygnathus assemblage (/level) and per taxonomic group (/level+species). N, sample size; R, Pearson correlation between the scores along the bgPC1 axes and the palaeoenvironmental proxies; $\mathrm{p}<0.001$ in bold; $\mathrm{p}<0.05$ in italic (after Girard et al. 2020a). 
Although it is difficult to reconstruct functional constraints related to pairing in isolated elements, the threedimensional reconstructions delivered by the morphometric analysis of Po. glaber and Po. communis (Fig. 5) may shed further light on the constraint relating the geometry of the elements to their interlocking.

In Po. glaber, the posterior margin extended more ventrally than the anterior one (Fig. 11), in contrast with the situation in Po. xylus. However, this trend is more marked on the left element (Fig. 11C). On the left element, the posterior margin extends more ventrally, the posterior platform is more elevated and displays a shallower groove, as confirmed by the example of actual elements (Fig. 11D). The reverse is true for the right element, with, however, less offset between the ventral extension of the posterior and anterior margins. The consequence is a marked bilateral asymmetry, in agreement with the high percentage of correctly classified right and left elements, suggestive of directional asymmetry, defined as consistent differences between right and left forms (Palmer 2004).

Such asymmetry imposes a constraint on the pairing of right and left elements: the deeper groove should be situated in front of the opposite blade; a shallow groove could not properly accommodate the blade coming into contact. This constraint may however be mitigated by variations in the height of the carina.

In Po. communis, the bilateral asymmetry is less pronounced: right and left elements differ only slightly, but they tend to display opposite patterns. The posterior margins tend to extend more ventrally and be more elevated in left elements, and the anterior margin in right elements (Fig. 11E, F). The slight geometric difference may be partly the cause of the moderate percentages of correct reassignment between right and left elements. The anterior and posterior grooves appear of comparable depth. Little constraint seems to exist on the interlocking of the elements, with grooves that could accommodate the opposite blade on both sides.

$3 D$ insight into allometric variation within Po. communis and Po. glaber

The three-dimensional geometric morphometric analysis further showed that the two species differed in their

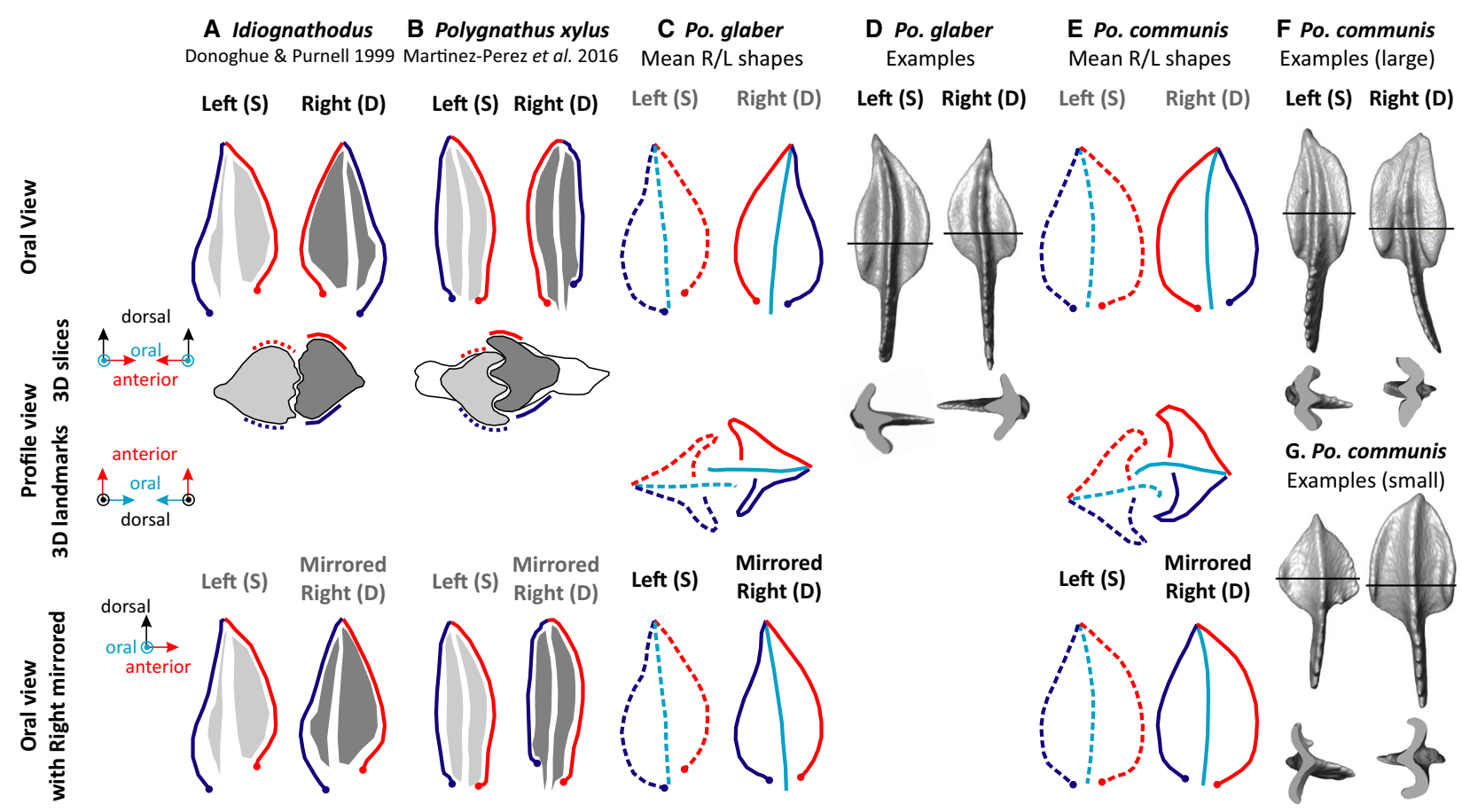

FIG. 11. Sketches summarizing morphological differences between right and left conodont elements based on known clusters (A, B) and the results of the present study. C, E, mean 3D shapes obtained by the geometric morphometric analysis of bilateral asymmetry in Polygnathus glaber (C) and Po. communis (E). D, F, G, illustrations based on isolated right and left elements of Po. glaber (D), large Po. communis (F) and small Po. communis (G). A-E, top panels, oral view; middle panels, profile view (actual slides above, 3D landmarks below); bottom panels, oral views, with elements as measured for the geometric morphometric analysis (mirror images of right elements). Black text, actual observations; grey text, modified representation. Specimens figured: D, Po. glaber right (UM BUS 027) and left (UM BUS 026); F, large Po. communis left (UM CTB 010) and right (UM CTB 009); G, small Po. communis left (UM CTB 006) and right (UM CTB 003). 
allometric relationships, although in Po. communis as in Po. glaber, large-sized elements shared an elongated platform shape with elevated margins delineating grooves. In contrast, small-sized elements were relatively flat, being wide and heart-shaped in Po. communis and narrow, drop-shaped in Po. glaber. Especially in small Po. communis, no proper grooves are delineated (Fig. 11G).

The small-sized elements therefore seem to offer few constraints for stabilizing the movement of the opposite blade. This may be related to the fact that they may not be functional. Distinct geochemical signatures and morphologies between small and large elements of the same species, and the lack of wear in the early stages, suggested that conodonts might have assumed their mature feeding habit only after an initial stage characterized by a different feeding mode (Shirley et al. 2018).

Altogether, these results show that bilateral asymmetry varied between species, leading to different functional constraints during pairing, and that these constraints varied with the allometric growth of the elements, possibly in relation with their acquisition of mature feeding behaviour.

Changing balance between allometry and asymmetry among Polygnathus species

The fact that the 2D morphometric description provided an efficient approximation of the $3 \mathrm{D}$ geometry allowed to explore the patterns of allometry and bilateral asymmetry among other Late Devonian Polygnathus species. Confirming the results obtained for Po. communis and Po. glaber based on 3D descriptors, the patterns related to bilateral asymmetry and to allometry, and their relative importance, varied among species. Allometry explained from almost $30 \%$ of within-group variance in Po. communis to hardly $2 \%$ in Po. diversus. The variation in the allometric direction of shape changes greatly contributed to the complex pattern of total morphological variation (Fig. 6). However, the allometric trajectory of all species converged, for large-sized specimens, towards elongated platforms typical of Polygnathus. This is probably due to functional constraints related to efficient pairing in mature specimens involved in the comminution of food particles, in contrast with few or no such constraints on small, non-functional elements, due to changes in feeding behaviour through ontogeny (Zhuralev 1995; Shirley et al. 2018). This may explain the variation of allometric trajectories even among closely related species (Jones 2009), leading to the suggestion that taxonomic studies should integrate the dimension of allometric variation (Chen et al. 2016).

Compared with allometric changes, the morphological differences associated with bilateral asymmetry were overall of smaller amount, ranging between 1.5 and $\sim 4 \%$ of within-group variance depending on the species. In all species, this signal was related to the first axis of total variance, thus involving a differential extension of the anterior or posterior margin of the platform. The percentage of correctly reclassified right and left elements provided an estimate of the consistency with which right and left elements differed: at the highest for Po. glaber, it was also high for Po. communis and Po. decorosus, but was hardly better or even worse than coin-flipping for $P o$. costatus and Po. diversus. Regarding Po. costatus, the absence of consistent signal may be due to the heterogeneity of the group encompassing a wide range of morphological variety.

The failure of the 2D morphometric approach to correctly assign right and left elements may be due to several causes. First, right/left differences may be consistent but too subtle to be captured by the morphometric descriptors. Second, the differences may not be as consistent as expected. Directional asymmetry is characterized by consistent differences between right and left forms (Palmer 2004); however, as is known from right-handedness in humans (Lazenby et al. 2008), directional asymmetry may not be completely fixed. Our results suggest different degrees of asymmetry consistency among species. Right/left differences may be fixed in some species such as Po. glaber, but not in other such as Po. costatus for which few right elements plotted with most left elements, and vice-versa. This might be suggestive of the occurrence of few 'left-handed' elements, here corresponding to left elements with an extended and elevated anterior margin, or right elements with an extended and elevated posterior margin.

Finally, another type of bilateral asymmetry can be expressed as a continuous variation with a mode corresponding to symmetry (right - left $=0$ ): covariant asymmetry (Palmer et al. 1993). Both right and left elements could display variation in the extension of their anterior and posterior margins, with many elements with both margins extending equally, up to left elements with an extended and uplifted posterior margin, and right elements with extended and uplifted anterior margin. In that case, the symmetrical elements would be difficult to reclassify, lowering the rate of correct assignation. The distribution of the shapes of right and left elements would also depend, in this case, of how pairing occurred: morphologies with an important offset between anterior and posterior margins, similar in the right and left elements, could be paired (as in Idiognathodus) or elements with different shapes could be paired, one with few and the other with a marked offset between the anterior and posterior margins (as in Po. xylus and Po. glaber).

To go a step further, in some species the case of a small percentage of 'left-handed' elements might even question the rule of the left element inserting behind the right one, 
if the 'left-handed' morphology impeded the regular pattern of occlusion. This would be the case, in the case of Po. glaber, of a right element displaying the left morphology: its elevated posterior margin would impede the insertion of the left blade behind the right one. Note, however, that the finding of 'left-handed' clusters may be very unlikely, first because several species probably displayed strict 'right-handedness', and second because even in the other species, 'left-handedness' might be the exception rather than the rule. Although speculative, this hypothesis can be considered since the sense of pairing indeed varied. The genus Palmatolepis is attributed to the same order (the Ozarkodinida) as Polygnathus (Donoghue et al. 2008) and in this genus, one and even possibly two clusters have been found suggesting that the right blade inserted behind the left one (Donoghue 2001a, b). Alternatively, variation of the curvature itself might be possible. A reversion of the curvature would lead to left elements with the convex side pointing backwards; without changing the pattern of pairing, with the left blade behind the right one, this would lead to wrong assignment of some elements to the right or left side, consequently decreasing the rate of correct reclassification when performing discriminant analyses between sides. Although this hypothesis seems very conjectural, one case in which the element conventionally regarded as right (dextral) was found on the left side of an apparatus has indeed been described (Aldridge et al. 2013). Nevertheless, so far, the only documented Polygnathus clusters are in agreement with the conventional pattern of pairing. Further studies focused on detecting facets due to the contact between blades could shed further light on the variation of the pairing pattern, especially since they can be performed on isolated elements, as the present morphometric analyses.

The degree of bilateral asymmetry between right and left elements, the consistency of the difference, and the constraints imposed on the pairing during occlusion seem thus remarkably variable among species, a trait that may be a key of the long-term diversification of Polygnathus (Martínez-Pérez et al. 2016) but that cannot be completely addressed based only on the few clusters available. Geometric morphometric approaches, allowing to assess the intraspecific variation, may be precious complements to the study of actual clusters. Developing 3D descriptors of the whole oral surface (e.g. Renaud \& Ledevin 2017) may further allow the description of features such as the adcarinal grooves.

\section{Indirect environmental forcing and remodeling of the ecosystem}

The within-group variation, including allometry and bilateral asymmetry, appeared to be of overwhelming importance when analysing the total shape variation (Fig. 6). The fact that allometric pattern changed among the groups hindered our ability to simply extract size-free parameters using a multivariate regression of shape versus size, as has been done for the Frasnian Ancyrodella (Girard \& Renaud 2008). Taxonomic and temporal differences could only be identified by focusing on betweengroup variation, which opposed slender, elongated with wide average platform shape, the most extreme group being Po. communis because the estimation of average shape includes small, heart-shaped elements (Fig. 7).

Both outcrops provided very similar patterns suggesting that, in this palaeogeographic area, the end of the Frasnian and the beginning of the Famennian were dominated by slender mean platform shapes, shifting towards wider elements around $365 \mathrm{Ma}$ (Pa. marginifera utahensis Zone; Fig. 10). This shift was primarily the result of a species replacement: typical slender species (e.g. Po. diversus) disappeared $\sim 364 \mathrm{Ma}$ ago (Scaphignathus velifer velifer Zone), concomitantly with the rise of the heart-shaped Po. communis. However, Po. glaber and Po. costatus also displayed intraspecific trend towards wider elements, launched before the disappearance of Po. diversus and amplifying the shape trend in the assemblage.

The two outcrops were located in similar latitudes but due to tectonic movements during the closing of the seaway between the remnant Rheic and Palaeotethys oceans, the global trends were expressed differently in the two areas (Girard et al. 2020a). Sea-water temperature decreased after $\sim 364 \mathrm{Ma}$ in the Col des Tribes (CT) whereas it remained more or less stable in Buschteich (BU) (Fig. 10). Since Polygnathus shape changed simultaneously in the two outcrops while the temperature did not, shape was only weakly related to this palaeoenvironmental proxy, contrary to what had been observed for Palmatolepis shape on a short time scale and during a period of rapid and pronounced temperature change at the end of the Frasnian and early Famennian (Balter et al. 2008). Only the shape variation of Po. brevilaminus appeared highly significantly related to temperature variations, as was observed for Palmatolepis within the Famennian (Girard \& Renaud 2012). Polygnathus brevilaminus was present in the records from the end Frasnian to the middle Famennian; its relationship with temperature may document a response to a first cooling step occurring towards $370 \mathrm{Ma}$ in the two outcrops.

In contrast to palaeotemperature records, which show a decoupling of the response in CT and BU after $365 \mathrm{Ma}$, conodont biofacies displayed marked and synchronous trends. The biofacies shift was mostly due to a decrease in abundance of Palmatolepis and a rise of Bispathodus, Polygnathus abundance remaining relatively moderate throughout (Girard et al. 2020a). This trend was launched around $365 \mathrm{Ma}$ ago, at the time when the shift 
towards wider mean shapes started in Polygnathus. As a consequence, both records were highly related. However, this clearly postponed the shift towards slender platform shapes that characterized Palmatolepis, and that was launched before $370 \mathrm{Ma}$ during the $\mathrm{Pa}$. delicatula platys Zone (Girard \& Renaud 2012). A direct forcing by abiotic factors can thus be discarded for Polygnathus and, even more so, a common forcing shared with Palmatolepis. The coupling with the biofacies record rather argues for changes in biotic interactions, such as changes in food resources differently impacting the different conodont genera, and/or competition between conodont genera. This seems to have driven first an intraspecific response within Po. glaber and Po. costatus, followed by a species replacement.

\section{CONCLUSION}

The present study relied on a 3D analysis of a subset of conodonts, and on a 2D study including more than 1500 conodonts. A comparison validated the $2 \mathrm{D}$ description as an efficient approximation of the 3D geometry, allowing the analysis of extensive sampling due to the reduced costs of the $2 \mathrm{D}$ analysis in terms of manpower and expense. Both 2D and 3D analyses showed that extensive within-species variation largely obliterated taxonomic and temporal differences in Polygnathus P1 elements. Allometry and bilateral asymmetry were important components of this intraspecific variation, but they varied among species both in their relative amount and the shape change involved. Allometry was most pronounced in Po. communis, leading from small, heart-shaped to large, lanceolate platforms. Bilateral asymmetry was most pronounced in Po. glaber, suggestive in this species of a strict directional asymmetry. 3D models suggest that the geometric differences between right and left elements could be associated with the asymmetrical pairing of the elements during occlusion, the left blade being assumed to insert behind the right one, based on existing clusters. In several species, however, right/left differences were not consistent enough to be captured by the morphometric description. It is possible that covariant asymmetry or even a certain percentage of reverted directional asymmetry may occur in some species. This suggests that the constraints imposed on pairing by the morphology of the elements, and the pattern of bilateral asymmetry, varied even among related species, to a greater extent than expected based on the few clusters available. Analysis of the within-species morphological variation through time may help to understand how functioning and constraints related to occlusions evolved along the diversification of Polygnathus, in the absence of documented clusters for many species.
Acknowledgements. We thank Dieter Weyer (Berlin, Germany), Konrad Bartzsch (Saafeld, Germany), Raimund Feist and JeanJacques Cornée (Montpellier, France) for their contribution during field trips. This paper benefited from the expertise of Carlo Corradini (Cagliari, Italy) who checked determinations of the Polygnathus species. We acknowledge the contribution of SFR Biosciences (UMS3444/CNRS, US8/Inserm, ENS de Lyon, UCBL) AniRa-ImmOs facility, and we particularly thank Mathilde Bouchet and Louise Souquet for their kind assistance during the scanning sessions. We further thank two anonymous reviewers, T. Hogancamp and C. Martinez-Perez for their constructive remarks on our manuscript. This work was supported by the ANR Project ECODEV (ANR-13-BSV7-005) and the LabEx CeMEB project MARCON. This is publication ISEM 2020-226.

\section{DATA ARCHIVING STATEMENT}

Data for this study are available in the Dryad Digital Repository: https://doi.org/10.5061/dryad.mgqnk98xf. 3D models (Po. glaber, Buschteich section: UM BUS 001 to 030; Po. communis, Col des Tribes section: UM CTB 001 to 034) are available in MorphoMuseuM: https://doi.org/doi.org/10.18563/journal.m3.126

Editor. Stephan Lautenschlager

\section{REFERENCES}

ADAMS, C. D. and OTAROLA-CASTILLO, E. 2013. geomorph: an $\mathrm{R}$ package for the collection and analysis of geometric morphometric shape data. Methods in Ecology \& Evolution, 4, 393-399.

— ROHLF, F. J. and SLICE, D. E. 2013. A field comes of age: geometric morphometrics in the 21th century. Hystrix, 24, 7-14.

ALDRIDGE, R. J., BRIGGS, D. E. G., CLARKSON, E. N. K. and SMITH, M. P. 1986. The affinities of conodonts new evidences from the Carboniferous of Edinburgh, Scotland. Lethaia, 19, 279-291.

- SMITH, M. P., NORBY, R. D. and BRIGGS, D. E. G. 1987. The architecture and function of Carboniferous polygnathacean conodont apparatus. 63-76. In ALDRIDGE, R. J. (ed.) Palaeobiology of conodonts. Ellis Horwood.

- BRIGGS, D. E. G., SMITH, M. P., ClARKSON, E. N. K. and CLARK, N. D. L. 1993. The anatomy of conodonts. Philosophical Transactions of the Royal Society B, 340, 405-421.

- MURDOCK, D. J. E., GABBOTT, S. E. and THERON, J. N. 2013. A 17-element conodont apparatus from the Soom Shale Lagerstätte (Upper Ordovician), South Africa. Palaeontology, 56, 261-276.

BALTER, V., RENAUD, S., GIRARD, C. and JOACHIMSKI, M. M. 2008. Record of climate-driven morphological changes in $376 \mathrm{Ma}$ Devonian fossils. Geology, 36, 907-910.

— MARTIN, J. E., TACAIL, T., SUAN, G., RENAUD, S. and GIRARD, C. 2019. Calcium stable isotopes place Devonian conodonts as first level consumers. Geochemical Perspectives Letters, 10, 36-39. 
BECKER, R. T., GRADSTEIN, F. M. and HAMMER, O. 2012. The Devonian period. 559-602. In GRADSTEIN, F. M., OGG, J. G., SCHMiTZ, M. D. and OGG, G. M. (eds). The geologic time scale 2012. Elsevier.

BOYER, D. M. 2008. Relief index of second mandibular molars is a correlate of diet among prosimian primates and other euarchontan mammals. Journal of Human Evolution, 55, 11181137.

BRIGGS, D. E. G., CLARKSON, E. N. K. and ALDRIDGE, R. J. 1983. The conodont animal. Lethaia, 16, 1-14.

CHEN, Y., NEUBAUER, T. A., KRYSTYN, L. and RICHOZ, S. 2016. Allometry in Anisian (Middle Triassic) segminiplanate conodonts and its implications for conodont taxonomy. Palaeontology, 59, 725-741.

Culhane, A. C., PERrière, G., CONSidine, E. C., COTTER, T. G. and HIGGINS, D. G. 2002. Between-group analysis of microarray data. Bioinformatics, 18, 1600-1608.

DONOGHUE, P. C. 2001a. Microstructural variation in conodont enamel is a functional adaptation. Proceedings of the Royal Society B, 268, 1691-1698.

_ 2001b. Conodonts meet cladistics: recovering relationships and assessing the completeness of the conodont fossil record. Palaeontology, 44, 65-93.

— and PURNELL, M. A. 1999. Mammal-like occlusion in conodonts. Paleobiology, 25, 58-74.

— FOREY, P. L. and ALDRIDGE, R. J. 2000. Conodont affinity and chordate phylogeny. Biological Reviews, 75, 191251.

- PURNELL, M. A., ALDRIDGE, R. J. and ZHANG, S. 2008. The interrelationships of 'complex' conodonts (Vertebrata). Journal of Systematic Palaeontology, 6, 119-153.

DRAY, S. and DUFOUR, A.-B. 2007. The ade4 package: implementing the duality diagram for ecologists. Journal of Statistical Software, 22, 1-20.

EVIN, A., CUCCHI, T., CARDINI, A., STRAND VIðARSDÓTTIR, U., LARSON, G. and DOBNEY, K. 2013. The long and winding road: identifying pig domestication through molar size and shape. Journal of Archaeological Science, 40, 735-743.

FRANKE, W., COCKS, L. R. M. and TORSVIK, T. H. 2017. The Palaeozoic Variscan oceans revisited. Gondwana Research, 48, 257-284.

GAUCHEY, S., GIRARD, C., ADNET, S. and RENAUD, S. 2014. Unsuspected functional disparity in Devonian fishes revealed by tooth morphometrics? Naturwissenschaften, 101,735-743.

GIRARD, C. and RENAUD, S. 2008. Disentangling allometry and response to Kellwasser anoxic events in the Late Devonian conodont genus Ancyrodella. Lethaia, 41, 383-394.

_ 2012. Disparity changes in $370 \mathrm{Ma}$ Devonian fossils: the signature of ecological dynamics? PLoS One, 7, e36230.

— CORNÉE, J.-J., CORRADINI, C., FRAVALO, A. and FEIST, R. 2014. Palaeoenvironmental changes at Col des Tribes (Montagne Noire, France), a reference section for the Famennian of north Gondwana-related areas. Geological Magazine, 151, 864-884.

CHARRUAULT, A.-L., CORRADINI, C., WEYER, D., BARTZSCH, K., JOACHIMSKI, M. M. and FEIST, R. 2017. Conodont biostratigraphy and palaeoenvironmental trends during the Famennian (Late Devonian) in the Thuringian Buschteich section (Germany). Newsletters on Stratigraphy, 50, 71-89.

JOACHIMSKI, M. M., CHARRUAULT, A.-L., DUfOUR, A.-B. and RENAUD, S. 2020a. Paleogeographic differences in temperature, water depth and conodont biofacies during the Late Devonian. Palaeogeography, Palaeoclimatology, Palaeoecology, 549, 108852.

CHARRUAULT, A.-L., LEDEVIN, R. and RENAUD, S. 2020b. 3D models related to the publication: Patterns of bilateral asymmetry and allometry in the Late Devonian Polygnathus conodonts. MorphoMuseuM. https://doi. org/10.18563/journal.m3.126

GÓMEZ CANO, A. R., HERNÁNDEZ FERNÁNDEZ, M. and ÁLVAREZ-SIERRA, M. Á. 2013. Dietary ecology of Murinae (Muridae, Rodentia): a geometric morphometric approach. PLoS One, 8, e7908.

GUENSER, P., SOUQUET, L., DOLÉDEC, S., MAZZA, M., RIGO, M. and GOUDEMAND, N. 2019. Deciphering the roles of environment and development in the evolution of a Late Triassic assemblage of conodont elements. Paleobiology, 45, 440457.

HOGANCAMP, N. J., BARRICK, J. E. and STRAUSS, R. E. 2016. Geometric morphometric analysis and taxonomic revision of the Gzhelian (Late Pennsylvanian) conodont Idiognathodus simulator from North America. Acta Palaeontologica Polonica, 61, 477-502.

JI, Q. and ZIEGLER, W. 1993. The Lali section: an excellent reference section for upper Devonian in South China. Courier Forschungsinstitut Senckenberg, 157, 1-183.

JONES, D. 2009. Directional evolution in the conodont Pterospathodus. Paleobiology, 35, 413-431.

_ PURnell, M. A. and VON BitTer, P. H. 2009. Morphological criteria for recognising homology in isolated skeletal elements: comparison of traditional and morphometric approaches in conodonts. Palaeontology, 52, 1243-1256.

KLAPPER, G. 1971. Sequence within the conodont genus Polygnathus in the New York lower Middle Devonian. Geologica et Palaeontologica, 5, 59-79.

— and FOSTER, C. T. J. 1986. Quantification of outlines in Frasnian (Upper Devonian) platform conodonts. Canadian Journal of Earth Sciences, 23, 1214-1222.

— and LANE, H. R. 1985. Upper Devonian (Frasnian) conodonts of the Polygnathus biofacies, N.W.T., Canada. Journal of Paleontology, 59, 904-951.

KOvarovic, K., AiEllo, L. C., CARDini, A. and LOCKWOOD, C. A. 2011. Discriminant function analyses in archaeology: are classification rates too good to be true? Journal of Archaeological Science, 38, 3006-3018.

LANE, H. R. 1968. Symmetry in conodont element-pairs. Journal of Paleontology, 42, 1258-1263.

LANGSRUD, Ø. and MEVIK, B.-H. 2012. ffmanova: FiftyFifty MANOVA. v.1.0.0. https://CRAN.R-project.org/packa ge=ffmanova

LAZENBY, R. A., COOPER, D. M. L., ANGUS, S. and HALLGRÍMSSON, B. 2008. Articular constraint, handedness, and directional asymmetry in the human second metacarpal. Journal of Human Evolution, 54, 875-885. 
LINDE, M., PALMER, M. and GÓMEZ-ZURITA, J. 2004. Differential correlates of diet and phylogeny on the shape of the premaxilla and anterior tooth in sparid fishes (Perciformes: Sparidae). Journal of Evolutionary Biology, 17, 941-952.

MARTÍNEZ-PÉREZ, C., RAYFIELD, E. J., BOTELLA, H. and DONOGHUE, P. C. 2016. Translating taxonomy into the evolution of conodont feeding ecology. Geology, 44, 247-250.

OKSANEN, J., BLANCHET, F. G., KINDT, R., LEGENDRE, P., MINCHIN, P. R., O'HARA, R. B., SIMPSON, G. L., SOlyMOS, P., HENRY, M., STEVENS, H. and WAGNER, H. 2013. vegan: Community Ecology Package.2.5-4. http://CRAN.R-project.org/package=vegan

PALMER, A. R. 2004. Symmetry breaking and the evolution of development. Science, 306, 828-833.

- STROBECK, C. and CHIPPINDALE, A. K. 1993. Bilateral variation and the evolutionary origin of macroscopic asymmetries. Genetica, 89, 201-218.

PRICE, S. A., HOLZMAN, R., NEAR, T. J. and WAINWRIGHT, P. C. 2011. Coral reefs promote the evolution of morphological diversity and ecological novelty in labrid fishes. Ecology Letters, 14, 462-469.

PURNEll, M. A. and DONOGHUE, P. C. J. 1997. Architecture and functional morphology of the skeletal apparatus of ozarkodinid conodonts. Philosophical Transactions of the Royal Society B, 352, 1545-1564.

— and ALDRIDGE R. J. 2000. Orientation and anatomical notation in conodonts. Journal of Paleontology, 74, $113-122$.

— BELL, M. A., BAINES, D. C., HART, P. J. B. and TRAVIS, M. P. 2007. Correlated evolution and dietary change in fossil stickleback. Science, 317, 1887.

R CORE TEAM 2017. R: A language and environment for statistical computing. v3.5.2. https://www.R-project.org/

RENAUD, S. and GIRARD, C. 1999. Strategies of survival during extreme environmental perturbations: evolution of conodonts in response to the Kellwasser crisis (Upper Devonian). Palaeogeography, Palaeoclimatology, Palaeoecology, 146, 19-32.

- and LEDEVIN, R. 2017. Impact of wear and diet on molar row geometry and topography in the house mouse. Archives of Oral Biology, 81, 31-40.

— DUfour, A.-B., HARdouin, E. A., LEDEVIN, R. and AUFFRAY, J.-C. 2015. Once upon multivariate analyses: when they tell several stories about biological evolution. PLoS One, 10, e0132801.

— ECAlle, B., Claisse, P., Charruault, A.-L., LEDEVIN, R. and GIRARD, C. 2020. Data from: Patterns of bilateral asymmetry and allometry in Late Devonian Polygnathus conodonts. Dryad Digital Repository. https://doi.org/10. 5061/dryad.mgqnk98xf

ROHLF, F. J. 2010. TPSdig.2.16. http://life.bio.sunysb.ed u/morph/index.html

— and SLICE, D. 1990. Extensions of the Procrustes method for the optimal superimposition of landmarks. Systematic Zoology, 39, 40-59.

ROOPNARINE, P. D., MURPHY, M. A. and BUENING, N. 2004. Microevolutionary dynamics of the early Devonian conodont Wurmiella from the Great Basin of Nevada. Palaeontologia Electronica, 8, 31A.

SCHLAGER, S. 2017. Morpho and Rvcg - Shape analysis in $\{R\}$. 217-256. In ZHENG, G., LI, S. and SZEKELY, G. (eds). Statistical shape and deformation analysis. Academic Press.

SHIRLEY, B., GROHGANZ, M., BESTMANN, M. and JAROCHOWSKA, E. 2018. Wear, tear and systematic repair: testing models of growth dynamics in conodonts with high-resolution imaging. Proceedings of the Royal Society B, 285, 20181614.

SPALLETTA, C., PERRI, M. C., OVER, D. J. and CORRADINI, C. 2017. Famennian (Upper Devonian) conodont zonation: revised global standard. Bulletin of Geosciences, 92, $1-27$.

SWEET, W. C. 1988. The Conodonta: Morphology, taxonomy, palaeoecology and evolutionary history of a long-extinct animal phylum. Oxford Monographs on Geology \& Geophysics, 10. Oxford University Press, 212 pp.

ZHURALEV, A. V. 1995. Ontogeny and trophic types of some Tournaisian Polygnathacea (Conodonta). Courier Forschungsinstitut Senckenberg, 182, 307-312.

ZIEGLER, W. and SANDBERG, C. A. 1990. The late Devonian standard conodont zonation. Courier Forschungsinstitut Senckenberg, 121, 1-115.

ZIMMERMAN, A. N., JOHNSON, C. C. and POLLY, P. D. 2018. Taxonomic and evolutionary pattern revisions resulting fromgeometric morphometric analysis of Pennsylvanian Neognathodus conodonts, Illinois Basin. Paleobiology, 44, 660-683. 